\title{
Titanate Nanotubes Engineered with Gold Nanoparticles and Docetaxel to Enhance Radiotherapy on Xenografted Prostate Tumors
}

\author{
Alexis Loiseau ${ }^{1} \mathbb{C}$, Julien Boudon ${ }^{1, * \mathbb{C}}$, Alexandra Oudot ${ }^{2}$, Mathieu Moreau ${ }^{3}$, Romain Boidot ${ }^{4}$, \\ Rémi Chassagnon ${ }^{1}$, Nasser Mohamed Saïd ${ }^{5}$, Stéphane Roux ${ }^{5}\left(\mathcal{C}\right.$, Céline Mirjolet ${ }^{6,7, *(\mathbb{C})}$ and \\ Nadine Millot ${ }^{1, *} *$ it \\ 1 Laboratoire Interdisciplinaire Carnot de Bourgogne, UMR 6303, CNRS-Université Bourgogne \\ Franche Comté, BP 47870, 21078 Dijon Cedex, France; alexis_loiseau@yahoo.fr (A.L.); \\ remi.chassagnon@u-bourgogne.fr (R.C.) \\ 2 Preclinical Imaging Platform, Nuclear Medicine Department, Georges-Francois Leclerc Cancer Center, \\ 21079 Dijon Cedex, France; AOudot@cgfl.fr \\ 3 Institut de Chimie Moléculaire de l’Université Bourgogne, UMR 6302, CNRS-Université Bourgogne \\ Franche Comté, 21078 Dijon Cedex, France; mathieu.moreau@u-bourgogne.fr \\ 4 Department of Biology and Pathology of Tumors, Georges-François Leclerc Cancer Center-UNICANCER, \\ 21079 Dijon Cedex, France; RBoidot@cgfl.fr \\ 5 Institut UTINAM, UMR 6213, CNRS-Université Bourgogne Franche-Comté, 25030 Besançon Cedex, France; \\ said.nasser_mohamed@univ-fcomte.fr (N.M.S.); stephane.roux@univ-fcomte.fr (S.R.) \\ 6 INSERM LNC UMR 1231, 21078 Dijon Cedex, France \\ 7 Radiotherapy Department, Georges-Francois Leclerc Cancer Center, 21079 Dijon Cedex, France \\ * Correspondence: julien.boudon@u-bourgogne.fr (J.B.); CMirjolet@cgfl.fr (C.M.); \\ Nadine.Millot@u-bourgogne.fr (N.M.)
}

Received: 23 October 2019; Accepted: 2 December 2019; Published: 6 December 2019

\begin{abstract}
Nanohybrids based on titanate nanotubes (TiONts) were developed to fight prostate cancer by intratumoral (IT) injection, and particular attention was paid to their step-by-step synthesis. TiONts were synthesized by a hydrothermal process. To develop the custom-engineered nanohybrids, the surface of TiONts was coated beforehand with a siloxane (APTES), and coupled with both dithiolated diethylenetriaminepentaacetic acid-modified gold nanoparticles (Au@DTDTPA $\mathrm{NPs}$ ) and a heterobifunctional polymer ( $\left.\mathrm{PEG}_{3000}\right)$ to significantly improve suspension stability and biocompatibility of TiONts for targeted biomedical applications. The pre-functionalized surface of this scaffold had reactive sites to graft therapeutic agents, such as docetaxel (DTX). This novel combination, aimed at retaining the AuNPs inside the tumor via TiONts, was able to enhance the radiation effect. Nanohybrids have been extensively characterized and were detectable by SPECT/CT imaging through grafted Au@DTDTPA NPs, radiolabeled with ${ }^{111} \mathrm{In}$. In vitro results showed that TiONts-AuNPs-PEG 3000 -DTX had a substantial cytotoxic activity on human PC-3 prostate adenocarcinoma cells, unlike initial nanohybrids without DTX (Au@DTDTPA NPs and TiONts-AuNPs-PEG $\left.{ }_{3000}\right)$. Biodistribution studies demonstrated that these novel nanocarriers, consisting of AuNP- and DTX-grafted TiONts, were retained within the tumor for at least 20 days on mice PC-3 xenografted tumors after IT injection, delaying tumor growth upon irradiation.
\end{abstract}

Keywords: titanate nanotubes; gold nanoparticles; vectorization; nanocarrier; colloidal stability; docetaxel; cytotoxicity; biodistribution; radiotherapy; prostate cancer 


\section{Introduction}

Cancer remains one of the world's most devastating diseases with approximately $0.2 \%$ of people worldwide diagnosed with cancer at some point during their life [1]. However, even if mortality has a tendency to decrease, due to a better understanding of tumor biology and improvement of diagnostic tools and treatments, the prevalence of prostate cancer remains very high, especially in developed countries [2]. As an example, in 2019 in the United States, prostate cancer was the third-most diagnosed cancer, with close to 175,000 estimated new cases, corresponding to 1 prostate cancer over 10 detected cancers, being the second leading cause of cancer-related deaths in men with more than 31,000 estimated deaths [3]. In Europe, in 2018, the number of new prostate cancer cases was estimated at 450,000 [4].

Currently, anticancer chemotherapeutic agents such as docetaxel (DTX) are used to target tumor cells in prostate cancer treatment. DTX is an anti-mitotic chemotherapeutic agent, well known to decrease androgen receptor activation in castration-resistant prostate cancer cells $[5,6]$. It has been approved by Food and Drug Administration (FDA) in particular for the treatment of hormone-refractory prostate cancers [7]. Chemotherapy is often associated with radiotherapy (RT) to increase its efficiency during tumor treatment [8]. Nevertheless, injected drugs weakly reach tumor sites, and patients who undergo repeated treatments develop drug resistance within 24 months of initial exposure [6,9,10]. Thus, high doses, relative to the patient's needs, are administered, causing harmful side effects and excessive toxicities [11-13].

The development of nanotechnologies has offered a new strategy to incorporate and vectorize an active substance specifically to sick cells, increasing its efficacy while limiting systemic concentration. Theranostic nanohybrids have been considerably developed over the past decade as a new generation of nanocarriers for therapeutic and diagnosis purposes [14,15]. This emergent nanotechnology can be used to control injected doses, to perform medical diagnostic imaging based on nanohybrids monitoring inside the organism, and to improve the intracellular concentration of drugs and allow their accumulation within tumor site by enhanced permeability and retention (EPR) mechanisms while limiting toxicity in normal tissues [16-19]. Nevertheless, further increasing treatment efficacy is a relevant issue. Direct tumor administration through intratumoral (IT) injection might be a relevant approach. Accordingly, there is an interest to develop new nanocarriers for docetaxel to increase therapeutic efficiency and enhance radiation sensitization by maintaining radiosensitizing agents inside cancer cells. Among all nanovectors, carbon nanotubes (CNTs) have been widely investigated for drug delivery applications [20] as well as halloysite clay nanotubes (HNTs) [21]. CNTs are pioneer nanovectors, representing a novel set of nanomaterials available for cancer therapy [22]. Their unique physicochemical properties and their ability to cross cell membranes provide a higher capacity of drug loading when compared to conventional liposomes and dendrimer drug carriers [23]. In addition, CNTs may prolong circulation time and improve bioavailability of conjugated drug molecules [24]. However, these molecules are largely insoluble. To become biologically compatible, appropriate surface modifications leading to a better water solubility should be envisaged [25]. As for HNTs, considered as viable and inexpensive nanoscale containers for encapsulation of drugs [26,27], they also require surface modification for increased colloidal stability, and even though some coated HNTs are evaluated as being non-cytotoxic up to $75 \mu \mathrm{g} \cdot \mathrm{mL}^{-1}$ [27], some others appear to have toxic effects [28]. To overcome CNT and HNT drawbacks, titanate nanotubes (TiONts) have received particular attention as a new generation of nanovectors with adequate surface chemistry that are highly adaptable when compared to the relatively inert chemistry of CNTs. Similarly, TiONts are widely studied [29-31] in a broad range of applications since their discovery in the late 1990s [32]. Recently, TiONt applications have been developed in several fields of biomedicine [29,33], such as orthopedics and dental implants [34], dopamine detection [35], DNA transfection [36] and adsorption [37], bioimaging [38,39], safe nanocarrier [36,40,41], drug delivery (genistein and docetaxel) [42-44], and cancer cell radiosensitization [44,45]. These TiONt applications are possible due to the atypical morphology shared with CNTs and HNTs. However, they present a shorter length (about 100-300 nm), an opening at the extremities, and a wide versatility of 
surface chemistry compared with CNTs [29]. It has been shown that shape and functionalization of nanoparticles, used as carriers, affects biodistribution $[19,46]$. Moreover, our group demonstrated that TiONts can be internalized with no cytotoxicity induction and maintained inside cells for at least 10 days in vitro [36,45]. Finally, the exposure to TiONts combined with irradiation induced a radiosensitizing effect [45]. The functionalization of nanocarrier-TiONts is mandatory in order to have new or complementary functionalities such as stability and biocompatibility in physiological conditions for biomedical applications $[19,40,43,47]$. In addition, functionalization enables TiONts to carry therapeutic molecules and improves colloidal stability, required for vectorization applications. In very recent studies, our group has reported the use of TiONts as carrier for therapeutic molecules together with DTX (TiONts-DTX) into prostate tumor $[43,44]$. This nanocarrier was beforehand pre-functionalized with 3-aminopropyl triethoxysilane and with a hetero-bifunctional polymer (polyethylene glycol) to immobilize DTX by covalent linkages. In vivo tests with IT injections of TiONts-DTX showed that more than $70 \%$ of TiONt nanovectors were retained within the tumor for at least 7 days. In addition, the radiosensitizing effect of nanohybrids was evaluated on PC-3 tumors with and without RT. In both conditions, tumor growth was significantly slowed down in mice receiving TiONts-DTX compared to mice receiving free DTX. This work proved nanohybrids ability to remain inside the tumor, increasing therapeutic efficiency.

Encouraged by these results, it was necessary to further improve the radiosensitizing effect of these nanohybrids. Over the past decade an increasing interest to use gold nanoparticles (AuNPs) as radiosensitizers for radiation therapy $[48,49]$ has arisen. AuNPs have the ability to combine imaging and therapy on the basis of the strong X-ray absorption cross section due to the high atomic number $(Z)$ of gold $[49,50]$. They have been commonly used for imaging applications [51-54] and accumulate in tumors upon the delivery of diagnostic agents and therapeutic drugs, while being effectively excluded from healthy tissue [55-58]. AuNPs are biologically well-tolerated and present a low toxicity $[49,58,59]$. Among the numerous examples of gold nanoparticles, Au@DTDTPA NPs appear attractive for image-guided radiotherapy. The ultrasmall gold core confers to the nanoparticles an efficient radiosensitizing effect, which increased the efficiency of radiation therapy by twofold when tumor-bearing animals were treated by radiotherapy after IT injection of Au@DTDTPA NPs [60,61]. Moreover, the organic shell of these nanoparticles has been designed to immobilize gadolinium ions and radioisotopes (indium-111, ${ }^{111} \mathrm{In}$ ). Consequently, the biodistribution of Au@DTDTPA NPs can be monitored by magnetic resonance imaging (MRI), and by nuclear imaging (positron emission tomography-PET, and single photon emission computed tomography-SPECT) [62-64]. Biodistribution studies, performed by a combination of MRI and SPECT, highlighted the safe behavior of Au@DTDTPA NPs after intravenous (IV) injection (accumulation in tumor, no undesirable accumulation in healthy tissue and renal clearance) and provided useful data to determine the ideal delay between the IV injection of Au@DTDTPA NPs and irradiation [60,64]. The radiosensitizing effect of Au@DTDTPA NPs can therefore be better exploited thanks to the possibility of following these nanoparticles by MRI. However, their potential is probably under-exploited due to their fast-renal clearance. The combination of Au@DTDTPA NPs with TiONts is expected to overcome this limitation by (i) the maintaining of nanotubes on site thanks to the design of nanohybrids compared to circulating nanovectors, (ii) improving the efficiency of nanohybrids in IT compared to IV even with the EPR effect, and (iii) the very possibility of combined injection of nanohybrids with radioactive iodine grains during brachytherapy [65]. Moreover, grafting gold nanoparticles onto TiONts, together with anticancer agents, paves the way to associate in the same entity, tumor retention, radiosensitization, and chemotherapy, and seems to be a new, attractive, and versatile platform.

This paper describes and analyzes each step required for the synthesis of a next generation nanohybrid. Analysis was performed using different characterization techniques (scanning transmission electron microscopy (STEM), thermogravimetric analysis (TGA), ל-potential measurement, $X$-ray photoelectron spectroscopy (XPS), Fourier-transformed infrared (FTIR), UV-visible and inductively coupled plasma (ICP) spectroscopies) as well as biological tests to evaluate efficacy against prostate cancer. Herein, 
we also report in vitro bioassays carried out on a human PC-3 prostate adenocarcinoma cells using 3-(4,5-dimethylthiazol-2-yl)-5-(3-carboxymethoxyphenyl)-2-(4-ulfophenyl)-2H-tetrazolium (MTS) assay. In vivo biodistribution assays were performed in PC-3 xenografted prostate tumors, after IT injection, on Balb/c nude male mice. The radiosensitizing efficacy of TiONts-AuNPs-PEG 3000 -DTX nanohybrids in association with RT, on a hormone-independent prostate cancer model, was also studied. Overall, these results describe the impact of a new generation TiONt-based treatment on a model of prostate cancer.

\section{Results}

The final nanohybrid (TiONts-AuNPs-PEG 3000 -DTX) was synthesized step-by-step from titanate nanotubes (TiONts) according to Loiseau et al. [43]. The strategy used to engineer a very versatile platform, which could be used for both nuclear imaging and therapy, is presented in Figure 1, even if the final end product is intended only for therapy and imaging being used only for preclinical developments. In this report, each grafting step has been characterized by different techniques. After hydrothermal synthesis of TiONts, morphological conformity was highlighted by transmission electron microscopy (TEM). As expected, a coiled spiral-shaped structure and an internal cavity, as described in $[41,43]$ and supporting information (Figure S1a) is shown. The observed dimensions are in agreement with literature on this compound, showing $(10 \pm 1) \mathrm{nm}$ in outer diameter, $(4 \pm 1) \mathrm{nm}$ in inner diameter, and $(170 \pm 50) \mathrm{nm}$ in length [29-32,43]. TiONts present a large specific surface area due to their tubular shape $\left((174 \pm 1) \mathrm{m}^{2} \cdot \mathrm{g}^{-1}\right)$, which is necessary to graft an important number of organic compounds. These ligands improve colloidal stability, dispersion state, and circulation time within the organism.

(i)

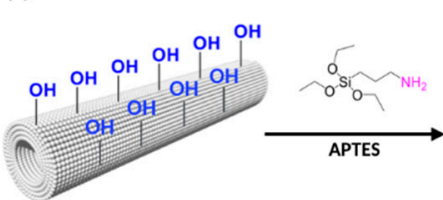

(a) TiONts

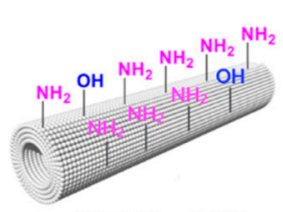

(b) TiONts-APTES

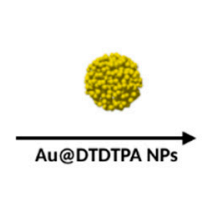

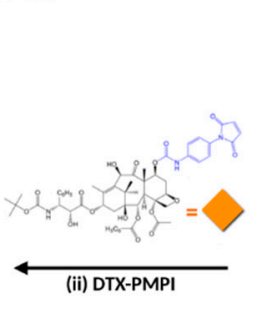

(ii) DTX-PMPI

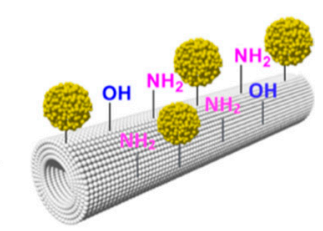

(c) TiONts-AuNPs
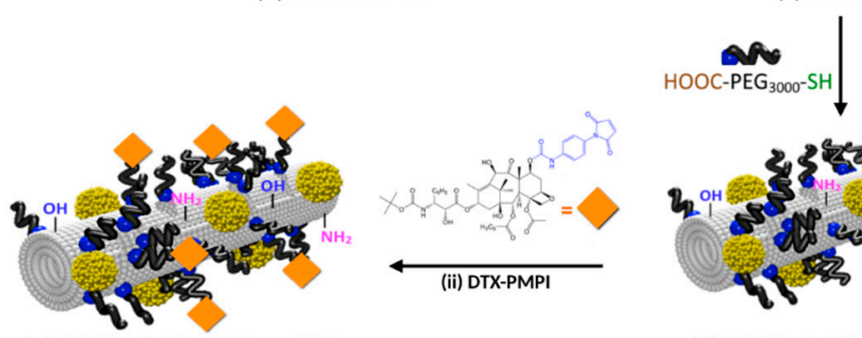

(e) TiONts-AuNPs-PEG 3000 -DTX

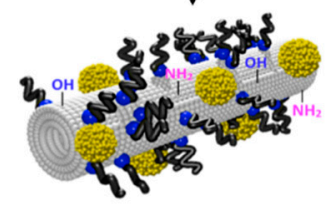

(d) TiONts-AuNPs-PEG 3000

(ii)

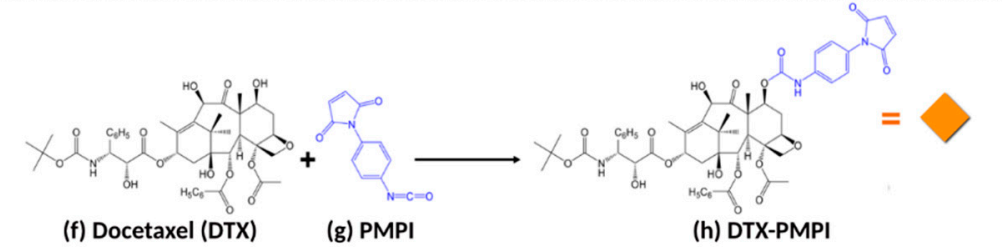

Figure 1. Illustration of (i) (a) titanate nanotubes (TiONts) and step-by-step pre-functionalization with (b) 3-aminopropyltriethoxysilane (APTES), (c) dithiolated diethylenetriaminepentaacetic acid-modified gold (Au@DTDTPA) nanoparticles (NPs), (d) $\alpha$-acid, $\omega$-thiol-polyethylene glycol (HS-PEG 3000 -COOH), and (e) $p$-maleimidophenyl isocyanate (PMPI)-modified docetaxel (DTX-PMPI) to yield the final nanohybrid-TiONts-AuNPs-PEG 3000 -DTX; (ii) this step corresponds to the modification of (f) DTX with (g) PMPI to form (h) DTX-PMPI (represented by an orange diamond).

In a previous work, TiONts, TiONts-APTES, and DTX-PMPI had already been characterized by several analysis techniques $[30,39,43]$. Briefly, grafting ratio on TiONts surface was determined by thermogravimetric analysis (TGA) (Figure 2). Results are reported in Table 1, and the details of the equations are given in Figures S2 and S3. 


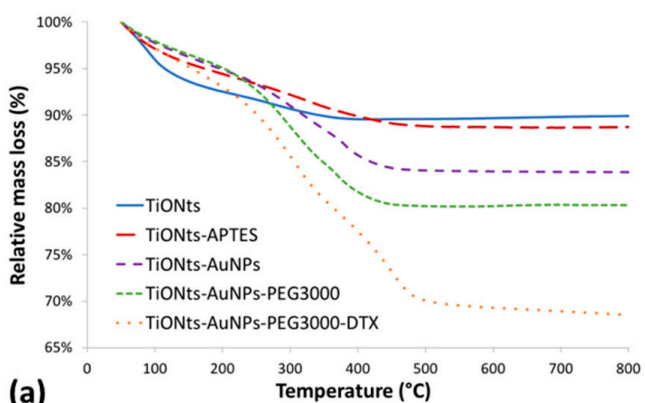

(a)

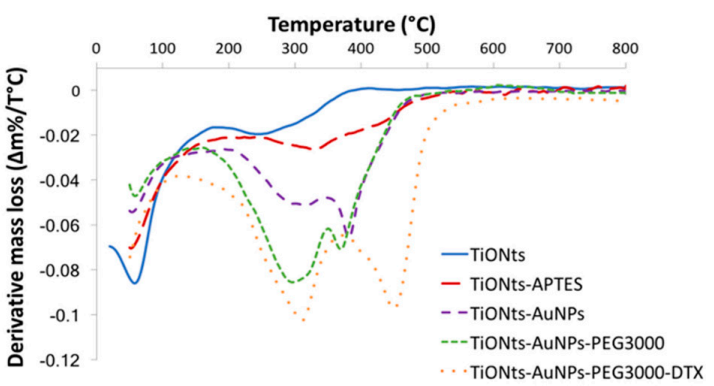

(b)

Figure 2. (a) Thermogravimetric analysis (TGA) and (b) derivative curves of bare TiONts and functionalized-TiONts under air atmosphere.

Table 1. Results of relative mass loss and graft ratio of bare TiONts and functionalized-TiONts.

\begin{tabular}{|c|c|c|c|c|c|c|}
\hline Nanohybrid Name & $\begin{array}{c}\text { Initial } \\
\text { Temperature of } \\
\text { Degradation }\left({ }^{\circ} \mathrm{C}\right)\end{array}$ & $\begin{array}{l}\text { Relative } \\
\text { Mass } \\
\text { Loss ( } \%)\end{array}$ & $\begin{array}{c}\text { Degraded } \\
\text { Molecular } \\
\text { Weight (g.mol }{ }^{-1} \text { ) }\end{array}$ & $\begin{array}{l}\text { Molecule.nm } \\
\text { (average) }\end{array}$ & $\underset{(n)}{\text { Reproducibility }}$ & $\begin{array}{c}\text { Number of } \\
\text { Grafted } \\
\text { Molecules Per } \\
\text { TiONt }^{1}\end{array}$ \\
\hline TiONts & 190 & 2.6 & 18 & $10.2( \pm 1.5) \mathrm{OH}$ & 10 & - \\
\hline TiONts-APTES & 175 & 6.3 & 58 & \multirow{2}{*}{$\begin{array}{c}2.6( \pm 0.2) \mathrm{NH}_{2} \\
0.40( \pm 0.05) \\
\text { DTDTPA }\end{array}$} & 9 & 14,230 \\
\hline TiONts-AuNPs & 150 & 12.4 & 511 & & 7 & 2,200 \\
\hline TiONts-AuNPs-PEG 300 & 150 & 16.1 & 3,073 & $\begin{array}{c}0.040( \pm 0.003) \\
\operatorname{PEG}_{3000}\end{array}$ & 4 & 220 \\
\hline TiONts-AuNPs-PEG 3000 & ${ }_{0}$-DTX 150 & 27.4 & 1,049 & $\begin{array}{l}0.30( \pm 0.01) \\
\text { DTX-PMPI }\end{array}$ & 2 & 1,700 \\
\hline
\end{tabular}

${ }^{1}$ The number of grafted molecules per TiONt was estimated by means of geometrical calculation considering only the external surface of TiONts.

Then, DTDTPA-modified gold nanoparticles were coupled with TiONts-APTES by peptide bond formation. Peptide coupling was performed between one of DTDTPA's carboxyl groups present in Au@DTDTPA NPs and an amine function on the TiONts-APTES surface. These Au@DTDTPA NPs are composed of a gold core with a diameter around $2.6 \mathrm{~nm}$ and a multilayered organic shell with approximately 120 DTDTPA per nanoparticle according to the literature $[52,62,64]$. Thanks to TGA, the graft ratio of DTDTPA on AuNPs was evaluated as 5.7 DTDTPA.nm ${ }^{-2}$ (Figure S4). The relative mass loss (Au@DTDTPA NPs) was 50\%, which led to molar ratio of 1:2.5 between DTDTPA and AuNPs, respectively. HAADF-STEM (high angle annular dark field scanning transmission electron microscopy) images highlighted the presence of gold nanoparticles on the nanotube surface and nowhere else on the grid, suggesting a good purification of ungrafted Au@DTDTPA NPs (Figure 3a,b). The grafting rate of gold nanoparticles on the TiONt surface was calculated and estimated between 20 and $40 \mathrm{AuNPs} / \mathrm{TiONt}$ using several techniques: STEM (via a STEM counting of about several hundred of nanotubes), TGA (the relative mass loss is due to DTDTPA molecules and was $0.40( \pm 0.05)$ DTDTPA.nm ${ }^{-2}$ of TiONts; Table 1), and a dosage via ICP (inductively coupled plasma). Then, comparing HAADF-STEM images before (Figure 3c,d) and after (Figure 3e,f) reflected the grafting step of $\mathrm{PEG}_{3000}$ on TiONts-AuNPs. 


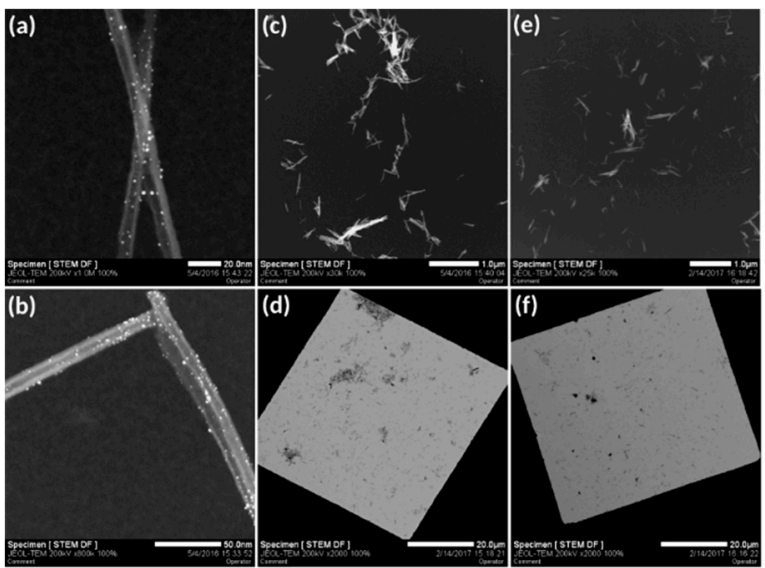

Figure 3. HAADF-STEM (high angle annular dark field scanning transmission electron microscopy) images showing $(\mathbf{a}, \mathbf{b})$ the grafting of Au@DTDTPA NPs on TiONts-APTES and the evolution of TiONts dispersion state (c,d) before (TiONts-AuNPs) and (e,f) after PEG 3000 grafting (TiONts-AuNPs-PEG 3000 ).

X-ray photoelectron spectroscopy (XPS) analyses were carried out to evaluate the chemical composition of the TiONts-AuNPs and TiONts-AuNPs-PEG 3000 surface (Figure 4 and Table 2).
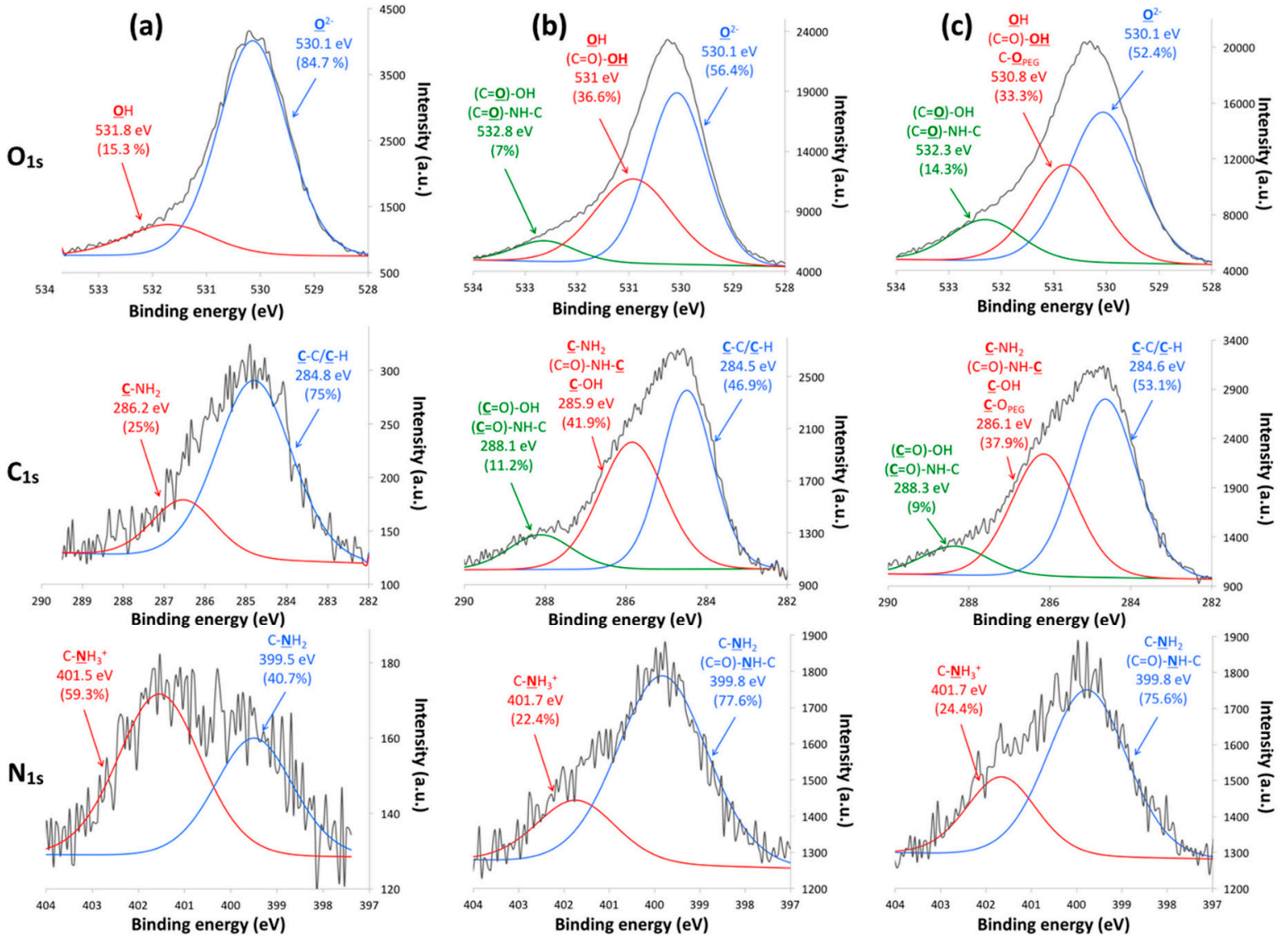

Figure 4. Fitted curves of $\mathrm{O}_{1 \mathrm{~s}}, \mathrm{C}_{1 \mathrm{~s}}$, and $\mathrm{N}_{1 \mathrm{~s}}$ peaks in XPS spectra for (a) TiONts-APTES, (b) TiONts-AuNPs, and (c) TiONts-AuNPs-PEG 3000 . 
Table 2. X-ray photoelectron spectroscopy (XPS) analyses: atomic concentration of bare TiONts, TiONts-APTES, TiONts-AuNPs, and TiONts-AuNPs-PEG 3000 .

\begin{tabular}{|c|c|c|c|c|c|c|c|}
\hline Atomic Concentration (\%) & $\mathrm{C}_{1 \mathrm{~s}}$ & $\mathrm{O}_{1 \mathrm{~s}}$ & $\mathrm{Na}_{\mathrm{KLL}}$ & $\mathrm{Ti}_{2 p}$ & $\mathbf{N}_{1 \mathrm{~s}}$ & $\mathrm{Si}_{2 \mathrm{p}}$ & $A \mathbf{u}_{4}$ \\
\hline TiONts & 7.3 & 58.7 & 13.5 & 20.5 & - & - & - \\
\hline Elements (TiONts)/Ti (\%) & 0.3 & 2.9 & 0.7 & 1.0 & - & - & - \\
\hline TiONts-APTES & 11.2 & 56.8 & 5.7 & 21.5 & 2.3 & 2.5 & - \\
\hline Elements (TiONts-APTES)/Ti (\%) & 0.5 & 2.6 & 0.3 & 1.0 & 0.1 & 0.1 & - \\
\hline TiONts-AuNPs & 18.5 & 54.1 & 1.4 & 19.2 & 3.1 & 2.5 & 1.2 \\
\hline Elements (TiONts-AuNPs)/Ti (\%) & 1.0 & 2.8 & 0.1 & 1.0 & 0.2 & 0.1 & 0.1 \\
\hline TiONts-AuNPs-PEG 3000 & 23.8 & 52.1 & 0.5 & 17.5 & 2.9 & 2.0 & 1.2 \\
\hline $\begin{array}{c}\text { Elements } \\
(\text { TiONts-AuNPs-PEG } 3000) / \mathrm{Ti}(\%)\end{array}$ & 1.4 & 3.0 & $\approx 0$ & 1.0 & 0.2 & 0.1 & 0.1 \\
\hline
\end{tabular}

FTIR spectroscopy was realized to confirm the effective coatings on TiONts (Figure 5a)-TiONts-APTES with the presence of amino-silane and the corresponding groups (Si-O-Si, $\mathrm{C}-\mathrm{C}-\mathrm{NH}_{2}, \mathrm{CH}_{2}$ ); TiONts-AuNPs following the grafting of gold nanoparticles onto TiONts by peptidic coupling $((\mathrm{C}=\mathrm{O})-\mathrm{N}-\mathrm{H}$ formation as well as $(\mathrm{C}=\mathrm{O})-\mathrm{OH}$ due to the DTDTPA coating of AuNPs); and finally $\mathrm{PEG}_{3000}$ on TiONts-AuNPs-PEG 3000 with a new C-O $\mathrm{O}_{\mathrm{PEG}}$ specific to the ethylene glycol repeat units. As far as surface modifications of TiONts are concerned, $\zeta$-potential measurements were realized to evaluate changes in terms of isoelectric points (IEP) and potential values at the physiological $\mathrm{pH}$ (Figure 5b).

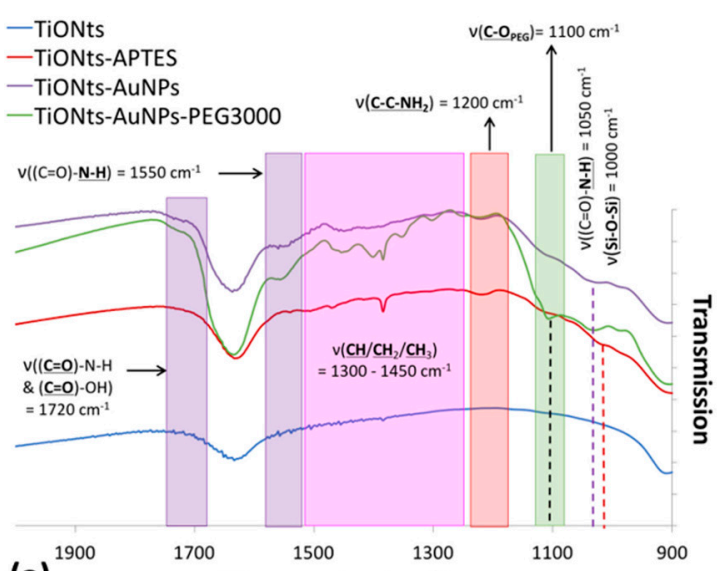
(a) Wavenumber $\left(\mathrm{cm}^{-1}\right)$

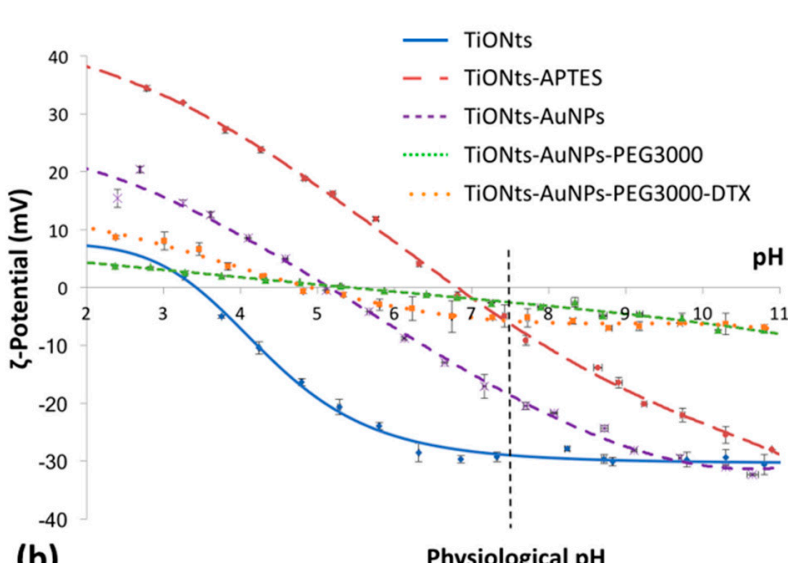

(b)
Physiological pH

Figure 5. (a) FTIR spectra of TiONts, TiONts-APTES, TiONts-AuNPs, and TiONts-AuNPs-PEG 3000 between $2000-900 \mathrm{~cm}^{-1}$ and (b) $\zeta$-potential curves of bare TiONts and different functionalized TiONts (the vertical dashed line corresponds to the physiological $\mathrm{pH}$ ).

To study the colloidal stability of TiONts nanohybrids in physiological conditions (phosphate buffered saline (PBS) buffer, pH 7.4), tubidimetric studies were realized (Figure 6a) by comparing the decrease in absorbance over time at the wavelength of $600 \mathrm{~nm}$. As expected, initial TiONts and simply modified TiONts-APTES exhibited the lowest stability compared to the further modifications of TiONts including AuNPs, PEG, and DTX, as can be seen also in the picture of the suspension of the final nanohybrids (Figure 6 b). 


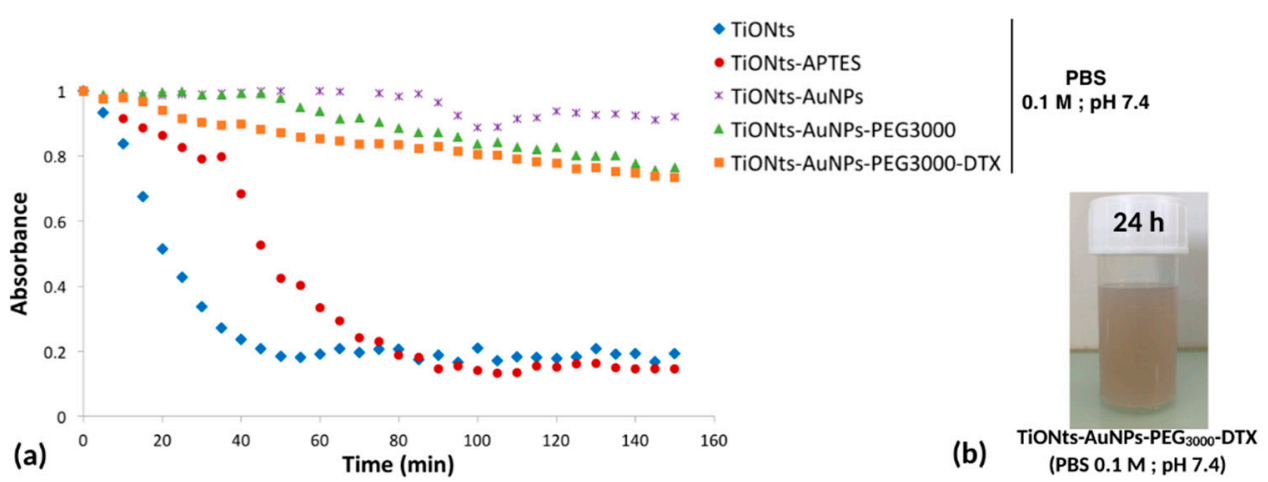

Figure 6. (a) Turbidimetric studies: colloidal stability of functionalized TiONt suspensions (phosphate buffered saline (PBS) $0.1 \mathrm{M}$; pH 7.4) over $150 \mathrm{~min}$ following their absorbance at $600 \mathrm{~nm}$ as a function of time. (b) Picture of a TiONts-AuNPs-PEG 3000 -DTX suspension in PBS (0.1 M; pH 7.4) after $24 \mathrm{~h}$.

MTS assays on a PC-3 human prostate cancer cell lines were performed to evaluate the cytotoxicity of DTX in the final nanohybrid (Figure 7a). Briefly, an increasing range of DTX (from $0.5 \mathrm{nM}$ to $500 \mathrm{nM}$ ) was used to evaluate the cytotoxicity of free DTX and TiONts-AuNPs-PEG ${ }_{3000}$-DTX. For a given DTX concentration, the committed quantity of TiONts-AuNPs-PEG 3000 (without DTX) (green curve) or $\mathrm{Au} @$ DTDTPA NPs (blue curve) corresponded to the quantity present on TiONts-AuNPs-PEG 3000 -DTX (orange curve).
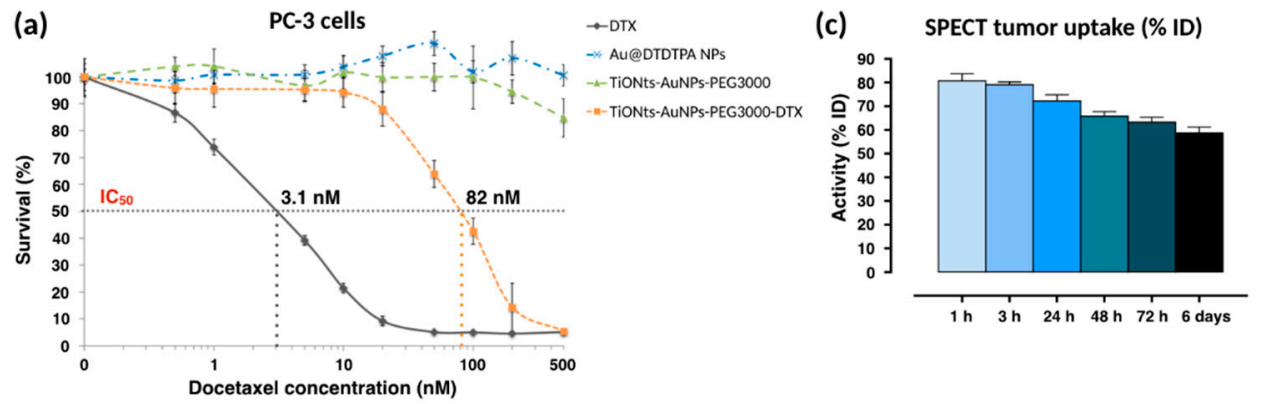

(b)

SPECT/CT imaging

(d) Biodistribution gamma counting
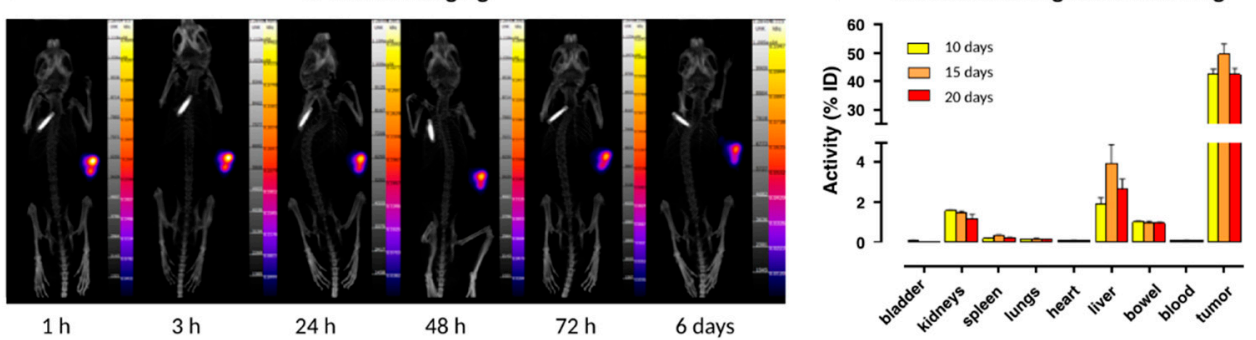

Figure 7. (a) Survival curves (3-(4,5-dimethylthiazol-2-yl)-5-(3-carboxymethoxyphenyl)-2-(4-ulfophenyl) -2H-tetrazolium (MTS) cytotoxicity assays) on PC-3 cell lines after incubation of DTX, Au@DTDTPA NPs, TiONts-AuNPs-PEG 3000 , and TiONts-AuNPs-PEG $3000-D T X$ (mean \pm SD). The studied range was from 0.5 to $500 \mathrm{nM}$ in DTX concentration, which also corresponded to a concentration range of $4.1 \times 10^{-3}$ to $4.1 \mu \mathrm{g} \cdot \mathrm{mL}^{-1}$ for TiONts-AuNPs-PEG 3000 and $3 \times 10^{-3}$ to $3 \mu \mathrm{g} \cdot \mathrm{mL}^{-1}$ for Au@DTDTPA NPs, present on the TiONts-AuNPs-PEG 3000 -DTX. The horizontal dotted line allows for an estimate of the different nanohybrids' $\mathrm{IC}_{50}$. (b) Single photon emission computed tomography coupled with a conventional scanner (SPECT/CT) imaging of kinetics and (c) SPECT tumor uptake (mean value \pm SD) achieved in Balb/c nude male mice after intratumoral (IT) injection of TiONts-AuNPs-PEG $3000-D T X-111$ In at $1 \mathrm{~h}, 3 \mathrm{~h}$, $24 \mathrm{~h}, 48 \mathrm{~h}, 72 \mathrm{~h}$, and 6 days (as a function of ${ }^{111}$ In injected activity (5.7-8.7 MBq) and corrected by ${ }^{111} \mathrm{In}$ radioactive decay). (d) TiONts-AuNPs-PEG $3000-\mathrm{DTX}-{ }^{111}$ In biodistribution in dissected organs (bladder, kidney, spleen, lung, heart, liver, bowel, blood, and tumor) by radioactivity detection using gamma counting 10, 15, and 20 days after IT injection (mean value \pm SD). 
The first in vivo biodistribution images, realized by SPECT coupled with a conventional scanner (SPECT/CT) after IT injection, showed that TiONts-AuNPs-PEG 3000 -DTX rabiolabeled with ${ }^{111}$ In were always retained within tumors six days after IT injection (Figure 7b). Moreover, from $24 \mathrm{~h}$ to 6 days, the remaining quantity of nanohybrids in tumors did not seem to decrease and proved the ability of the nanohybrid to maintain DTX and gold nanoparticles within tumors to increase their therapeutic efficacy, as more than $60 \%$ of the injected radiolabeled nanohybrids were still inside the tumor after 6 days (Figure 7c) and that there was therefore no release of the radiolabeled Au@DTDTPA (NPs)-they were still grafted to titanate nanotubes. Moreover, gamma counting confirmed these results because more than $42.5 \pm 3.7 \%$ of nanohybrids were still kept inside tumors 20 days after IT injection (Figure $7 \mathrm{~d}$ ).

Finally, the therapeutic effects on TiONt nanohybrids were investigated by the study of tumor growth delay until a tumor volume of $1000 \mathrm{~mm}^{3}$ was reached (Figure 8 and Figure S9) and in the presence or not of radiotherapy (RT). Differences were noted between treatments with or without RT and the final nanohybrids TiONts-AuNPs-PEG 3000 -DTX associated with RT showed (i) the longest delay before tumor growth (over 55 days) and (ii) a significant difference in delay compared to similar nanohybrids without AuNPs (28\% higher).

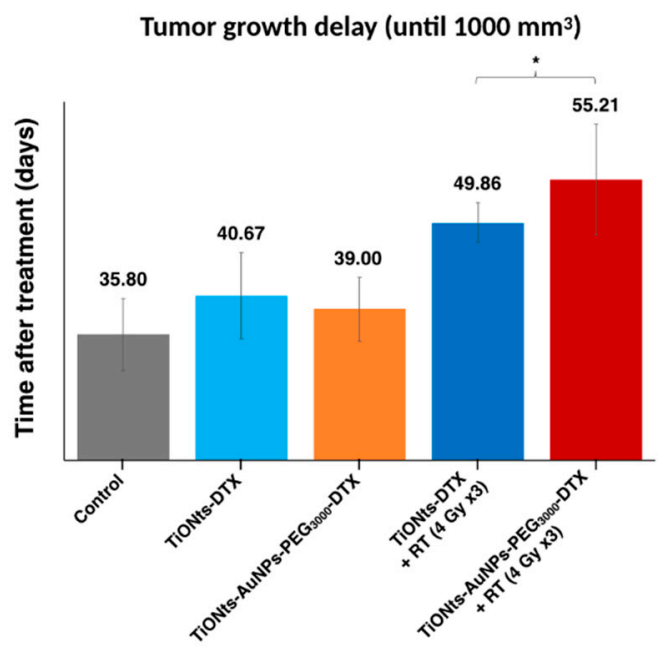

Figure 8. Therapeutic effect of control, TiONts-DTX, and TiONts-AuNPs-PEG 3000 -DTX, associated or not with radiotherapy (RT) administered with three daily fractions of $4 \mathrm{~Gy}$ (3 groups, $n=6-7$ ), after IT injection into PC-3 xenografted tumors. ${ }^{*} p=0.035$ (TiONts-AuNPs-PEG ${ }_{3000}$-DTX + RT vs. TiONts-DTX $+\mathrm{RT})$; comparison performed using nonparametric Mann-Whitney test.

\section{Discussion}

The applied functionalization protocol with 3-aminopropyl triethoxysilane (APTES) tended to limit the multilayered formation of this molecule on the surface of TiONts $[66,67]$. Thus, the grafting ratio of APTES (2.6 $\mathrm{NH}_{2} \cdot \mathrm{nm}^{-2}$ ) decreased significantly when compared to results available in the literature $[39,43]$. Moreover, TiONts-APTES enhanced tube individualization, as compared to bare nanotubes, for a suspension of equal concentration (Figure S1b,c). To some extent, a similar observation can be made on grafted AuNPs that did not seem to stick to each other and were relatively evenly distributed over the whole surface of TiONts.

From XPS analyses, gold was observed on TiONts-AuNPs and TiONts-AuNPs-PEG 3000 , which was consistent with the presence of AuNPs (Table 2 and Figure S5). In addition, other atoms such as nitrogen and silicon corresponding to APTES or even chemical elements identical to those of bare TiONts (Ti, O, and $\mathrm{Na}$ ) were found. Subsequently, the quantitative analysis revealed an increase in carbon and oxygen content for TiONts-AuNPs, in comparison to TiONts-APTES, consistent with the presence of DTDTPA on nanohybrid. Thereafter, increase of these same chemical elements also showed PEG $_{3000}$ grafting on TiONts-AuNPs-PEG ${ }_{3000}$. A significant decrease for chemical elements such as $\mathrm{Ti}_{2 \mathrm{p}}, \mathrm{O}_{1 \mathrm{~s}}$, and $\mathrm{Na}_{\mathrm{KLL}}$ was also observed, according to successive grafting. The decomposition of $\mathrm{O}_{1 \mathrm{~s}}, \mathrm{C}_{1 \mathrm{~s}}$, and $\mathrm{N}_{1 \mathrm{~s}}$ peaks in 
XPS spectra highlighted the formation of secondary amide bonds, characteristic of AuNPs grafting on TiONts via peptide coupling (EDC/NHS) as well as carboxyl functions from DTDTPA (Figure 4a,b). These same peaks also suggested the evolution of components associated to $\mathrm{PEG}_{3000}$ grafting via peptide coupling (PyBOP) on the remaining free amine functions, after covalent immobilization of Au@DTDTPA NPs (Figure 4c). Therefore, appearance of two new components was attributed to two types of bonds $((\underline{\mathrm{C}=\mathrm{O}})-\mathrm{NH}-\mathrm{C}$ and $(\underline{\mathrm{C}=\mathrm{O}})-\mathrm{OH})$ concerning TiONts-AuNPs and TiONts-AuNPs-PEG 3000 samples compared to TiONts-APTES, one of which was located at $532.8 \mathrm{eV}(7 \%)$ for the $\mathrm{O}_{1 \mathrm{~s}}$ peak and the other at $288.1 \mathrm{eV}(11.2 \%)$ for the $\mathrm{C}_{1 \mathrm{~s}}$ peak $[40,68]$. Moreover, the $\mathrm{O}_{1 \mathrm{~s}}$ region of TiONts-AuNPs-PEG 3000 showed an increase for the component located at $532.3 \mathrm{eV}$, indicating a higher peptide coupling rate and more carboxyl functions (from 7\% to $14.3 \%$ before and after $\mathrm{PEG}_{3000}$ grafting, respectively). Moreover, other components may be also assigned to carboxyl groups $((\mathrm{O}=\mathrm{C})-\mathrm{OH})$, such as those located at $\approx 531 \mathrm{eV}\left(\mathrm{O}_{1 \mathrm{~s}}\right)$ and $\approx 286 \mathrm{eV}\left(\mathrm{C}_{1 \mathrm{~s}}\right)$ [68]. These functions were responsible for the increase of these components in comparison to those observed at the same positions for TiONts-APTES-15.3\% $\left(\mathrm{O}_{1 \mathrm{~s}}\right)$ and $25 \%\left(C_{1 s}\right)$, respectively. These analyses were consistent with what was observed for $N_{1 s}$ peak for TiONts-AuNPs and TiONts-AuNPs-PEG 3000 , due to the increase of the $399.8 \mathrm{eV}$ component attributed to $((\mathrm{C}=\mathrm{O})-\underline{\mathrm{NH}}-\mathrm{C})$ groups as well as $\mathrm{C}-\mathrm{NH}_{2}$ bonds at the expense of $\mathrm{C}-\mathrm{NH}_{3}{ }^{+}(401.7 \mathrm{eV})$ with respect to the $\mathrm{N}_{1 \mathrm{~S}}$ region of TiONts-APTES [69]. With regards to TiONts-AuNPs-PEG ${ }_{3000}$, the decomposition of $\mathrm{C}_{1 \mathrm{~s}}$ and the $\mathrm{O}_{1 \mathrm{~s}}$ threshold highlighted the grafting of the polymer. The component associated with C-C/C-H groups at $284.6 \mathrm{eV}$ was more intense due to the PEGylated chains of $\mathrm{PEG}_{3000}$ (from $46.9 \%$ to $53.1 \%)$. Regarding the contributions of the $\mathrm{C}-\mathrm{O}_{\mathrm{PEG}}$ bond, they may be located at $530.8 \mathrm{eV}\left(\mathrm{O}_{1 \mathrm{~s}}\right)$ and $286.1 \mathrm{eV}\left(\mathrm{C}_{1 \mathrm{~s}}\right)[40,69]$.

FTIR spectroscopy confirmed the XPS results, thus showing the effective synthesis of TiONts-AuNPs and TiONts-AuNPs-PEG 3000 nanohybrids. Indeed, IR spectra show the appearance of new characteristic vibration bands in Figure $5 \mathrm{a}$, corresponding to the formation of amide bonds located at 1050 and $1550 \mathrm{~cm}^{-1}((\mathrm{C}=\mathrm{O})-\underline{\mathrm{N}-\mathrm{H}})$ as well as $1720 \mathrm{~cm}^{-1}((\underline{\mathrm{C}=\mathrm{O}})-\mathrm{N}-\mathrm{H})$. Furthermore, IR analysis was consistent in that Au@DTDTPA NPs remained on the surface of TiONts even after last synthesis steps, with the persistence of functions attributed to $(\mathrm{C}=\mathrm{O})-\mathrm{N}-\mathrm{H}$ and $(\mathrm{C}=\mathrm{O})-\mathrm{OH}$ of DTDTPA molecules

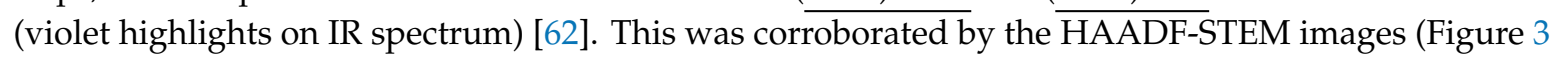
and Figure S6). Moreover, the strong absorption band at $1100 \mathrm{~cm}^{-1}$ (C-OPEG) was also observed (green highlights on IR spectrum) [47]. Finally, functions attributed to aliphatic carbon chains were increasingly intense due to the additional organic moieties after each grafting (APTES, Au@DTDTPA NPs, and $\mathrm{PEG}_{3000}$ ) on TiONts, and were located between 1450 and $1300 \mathrm{~cm}^{-1}$.

$\zeta$-potential measurements indicated an isoelectric point (IEP) at $\mathrm{pH} 6.9$ for TiONts-APTES. This value was higher than for bare TiONts (IEP 3.3) due to the coating of amine functions (Figure 5b). Therefore, the decrease in the number of amines partly engaged in Au@DTDTPA NPs coupling with TiONts-APTES and appearance of $\mathrm{COO}^{-}$groups from DTDTPA led to an IEP shifted downward to the lower $\mathrm{pH}$ value of 5.1 (violet curve). At $\mathrm{pH}$ 7.4, carboxylate functions significantly improved the $\zeta$-potential, in absolute value, favoring the electrostatic repulsion-from $-6 \mathrm{mV}$ (TiONts-APTES) to $-20 \mathrm{mV}$ (TiONts-AuNPs). Nevertheless, a significant screening effect was observed concerning $\mathrm{PEG}_{3000}$-functionalized TiONts (green curve) over the entire $\mathrm{pH}$ range studied ( $-2 \mathrm{mV}$ at $\mathrm{pH}$ 7.4). These results were striking when compared to a previous study [43], thus suggesting that the steric effect mainly governs colloidal stability at physiological $\mathrm{pH}$. The electrokinetic monitoring of TiONts-AuNPs-PEG 3000 -DTX (orange curve) showed a less pronounced screening effect $(-7 \mathrm{mV}$ at $\mathrm{pH}$ 7.4), even if the evolution of $\zeta$-potential measurements as a function of $\mathrm{pH}$ were very close to that of nanohybrid without DTX-PMPI. The strong screening effect was observed while the grafting of $\mathrm{Au} @ D T D T P A$ NPs induced a less important grafting density of $\mathrm{PEG}_{3000}$ on the surface of nanohybrid than without Au@DTDTPA NPs (0.04 PEG $3000 . \mathrm{nm}^{-2}$ for TiONts-AuNPs-PEG 3000 vs. 0.05 PEG $3000 . \mathrm{nm}^{-2}$ for TiONts-PEG 3000 ; Table 1) [43] due to the decrease in the number of free amines and steric hindrance. The lower coverage rate of polymer led to an area per chain of $25 \mathrm{~nm}^{2}$ (the PEG 3000 radius of gyration is about $2.5 \mathrm{~nm}$, which corresponded to a covering surface of $20 \mathrm{~nm}^{2}$ ), indicating a 
mushroom conformation [70]. However, this calculation did not consider the TiONts surface already occupied by gold nanoparticles. Therefore, the polymer could also have been in brush conformation onto nanohybrid.

DTX was modified by $p$-maleimidophenyl isocyanate (PMPI) to obtain an adequate function for the combination with TiONts-AuNPs-PEG 3000 . The reaction between PMPI and thiol groups was expected at $\mathrm{pH} 7.4$ in PBS, as maleimide reacts specifically with thiol in a $\mathrm{pH}$ range from 6.5 to 7.5 (Figure S7), whereas the reaction was possible both with thiol and amine functions above a $\mathrm{pH}$ of 7.5. The functionalization of TiONts-AuNPs-PEG 3000 with DTX-PMPI was observed by TGA. The relative mass loss of final nanohybrids was greater than that of TiONts-AuNPs-PEG 3000 , revealing the immobilization of therapeutic agent (DTX) on the surface of TiONts (Figure 2). The grafting ratio was estimated to 0.30 DTX-PMPI.nm ${ }^{-2}$ (Table 1) and higher than previously reported (0.20 DTX-PMPI.nm ${ }^{-2}$ ) [43]. Indeed, thiol functions brought both by DTDTPA and PEG 3000 could react with the maleimide group of DTX-PMPI in PBS (0.1 M; pH 7.4). However, despite repeated purifications, it cannot be excluded that DTX-PMPI clung/adsorbed to amine groups of APTES not functionalized by Au@DTDTPA NPs in the cavity of nanotubes and/or was trapped within PEGylated chains (Figure S8). Consequently, this enhancement of DTX quantity could increase the therapeutic effect of nanohybrid on tumor cells in addition to AuNPs.

Functionalization with Au@DTDTPA NPs and PEG $_{3000}$ enhanced tube individualization as compared to bare nanotubes at similar concentration (Figure $3 c-f$ ). Even if the graft ratio of $P E_{3000}$ was low, their presence seemed to limit nanohybrids agglomeration, comparing their dispersion with the STEM images of TiONts-AuNPs. The hypothesis, shown above, concerning the conformation of $\mathrm{PEG}_{3000}$ on the surface of TiONts (polymer brush conformation), could then be confirmed.

Colloidal stability of different functionalized TiONt suspensions was also investigated under physiological conditions (PBS 0.1 M; pH 7.4) by turbidimetric analyses (Figure 6a) and correlated with STEM images. Results demonstrated a very good colloidal stability of TiONts-AuNPs and TiONts-AuNPs-PEG 3000 in comparison with TiONts and TiONts-APTES. Indeed, the measured absorbance did not significantly change after $150 \mathrm{~min}$ for AuNP-functionalized TiONts. The grafting of DTX-PMPI on the surface of TiONts-AuNPs-PEG 3000 also did not lead to any major change on the colloidal stability of the final nanohybrid in PBS. Thus, colloidal stability was dramatically improved at physiological $\mathrm{pH}$ and was largely sufficient over time to in vivo inject the nanohybrid after radiolabeling the DTDTPA by ${ }^{111} \mathrm{In}$. Moreover, Figure $6 \mathrm{~b}$ shows that brown TiONts-AuNPs-PEG ${ }_{3000}$-DTX suspension was always stable after $24 \mathrm{~h}$ in PBS, proving the presence of gold nanoparticles (TiONts suspensions are white).

Initial results demonstrated that Au@DTDTPA NPs and TiONts-AuNPs-PEG 3000 did not exhibit any cytotoxicity in the studied range (either from $3 \times 10^{-3}$ to $3 \mu \mathrm{g} \cdot \mathrm{mL}^{-1}$ of Au@DTDTPA NPs and $4.1 \times 10^{-3}$ to $4.1 \mu \mathrm{g} . \mathrm{mL}^{-1}$ of TiONts-AuNPs-PEG 3000 ), whereas unmodified DTX showed cytotoxicity (black curve), with a half-maximum inhibitory concentration ( $\left.\mathrm{IC}_{50}\right)$ of $3.1 \mathrm{nM}$, in agreement with results previously shown in literature [43,71]. TiONts-AuNPs-PEG 3000 -DTX were still cytotoxic $\left(\mathrm{IC}_{50}: 82 \mathrm{nM}\right)$ even though they were less toxic than free DTX. Nevertheless, the cytotoxic efficacy of the final nanohybrid was higher with gold nanoparticles than what was previously observed for TiONts-DTX $\left(\mathrm{IC}_{50}=360 \mathrm{nM}\right)$, synthesized by Loiseau et al. [43]. Indeed, these nanohybrids being better dispersed and more stable in suspension have probably improved cell internalization by diffusion or endocytosis processes of current nanohybrids in sick cells [45] and led to a better access of DTX to microtubules. These achievements were very promising and allowed in vivo experiments on PC-3 xenografted tumors into Balb/c nude mice.

Twenty days after IT injection, a small amount of nanohybrids was found in other organs such as liver $(2.4 \pm 0.9 \%)$, kidney $(1.2 \pm 0.4 \%)$, lung $(0.10 \pm 0.01 \%)$, spleen $(0.20 \pm 0.05 \%)$, and bowel $(0.90 \pm 0.01 \%)$. Less than $0.1 \%$ of nanohybrids were detected in bladder, blood, and heart. The low quantities detected in different organs were correlated with the lack of toxicity shown during mice follow up, which lasted three months post-injection. 
Using this in vivo approach, we observed that tumor volumes revealed a slight growth delay after IT injection in mice. Indeed, TiONts-DTX and TiONts-AuNPs-PEG $3_{000}$-DTX groups without radiotherapy (RT) reached a volume of $1000 \mathrm{~mm}^{3}$ at a later time when compared with the control group ( $40.7 \pm 5.4$ days, $39 \pm 4$ days, and $35.8 \pm 4.5$ days, respectively) (Figure 8 ). This interesting effect may be explained by the retention of DTX within tumor cells by TiONt-based nanovectors improving therapeutic efficacy and preventing its diffusion throughout the body. Thus, these results are consistent with biodistribution analysis. Moreover, these observations have already been described in prior studies evaluating the efficacy of TiONts-DTX with and without RT, in comparison with groups receiving free DTX $[43,44]$. More importantly, we observed an improved therapeutic efficacy by combining TiONts-AuNPs-PEG ${ }_{3000}$-DTX with RT. Indeed, tumor growth was significantly slowed by TiONts-AuNPs-PEG 3000 -DTX associated with RT to reach a volume of $1000 \mathrm{~mm}^{3}$ (55.2 \pm 6.9 days), compared with TiONts-DTX with RT $(49.9 \pm 2.5$ days $)$ in the same conditions $(p=0.035)$. Thus, these results suggest that gold nanoparticles significantly improve the RT efficacy of nanohybrid even if the gold quantity injected (corresponding to $36.1 \mathrm{nmol}$ of $\mathrm{Au}$ or $66.5 \mathrm{pmol}$ of AuNPs and $15 \mu \mathrm{g}$ of Au@DTDTPA/animal) was significantly less than the quantity used in previous publication on Au@DTDTPA NPs alone (160 $\mu \mathrm{g}$ of Au@DTDTPA/animal) [61], thus showing the synergistic effect of the association of TiONts and AuNPs nanohybrids fulfilling their role as carriers by concentrating the therapeutic and chelating agents within cancer cells.

\section{Materials and Methods}

\subsection{Materials}

Titanium dioxide $\left(\mathrm{TiO}_{2}\right)$ rutile precursor was purchased from Tioxide (Calais, France). Sodium hydroxide $(\mathrm{NaOH}), 3$-aminopropyl triethoxysilane (APTES), ethanol, benzotriazole-1-yloxytripyrrolidinophosphonium hexafluorophosphate (PyBOP), $N, N$-diisopropylethylamine (DIEA), diethylenetriaminepentaacetic acid bis(anhydride) (DTPA-BA), tetrachloroauric acid trihydrate ( $\mathrm{HAuCl}_{4}$. $\left.3 \mathrm{H}_{2} \mathrm{O}\right)$, sodium borohydride $\left(\mathrm{NaBH}_{4}\right)$, acetic acid, methanol, dimethyl formamide (DMF), trimethylamine, and aminoethanethiol were acquired from Sigma-Aldrich (Saint-Quentin-Fallavier, France). A derivative of polyethylene glycol, named $\alpha$-acid, $\omega$-thiol-polyethylene glycol (HS-PEG $3000-\mathrm{COOH}, \mathrm{MW}=3073 \mathrm{~g} \cdot \mathrm{mol}^{-1}$ ), was purchased from Iris Biotech $\mathrm{GmbH}$ (Marktredwitz, Germany). N-hydroxysuccinimide (NHS), 1-ethyl-3-(dimethylaminopropyl) carbodiimide hydrochloride (EDC), $p$-maleimidophenyl isocyanate (PMPI), and tris(2-carboxyethyl)-phosphine hydrochloride (TCEP) were obtained from Thermo Scientific (Illkirch, France). Docetaxel (DTX) was purchased from BIOTREND Chemikalien GmbH (Cologne, Germany). Borate buffered saline was prepared from boric acid (99.8\%). Phosphate buffered saline (PBS) $1 \times$ solution (Fisher Bioreagents, Illkirch, France), dimethyl sulfoxide (DMSO extra dry, anhydrous 99.99\%) (Acroseal), and hydrochloric acid $(\mathrm{HCl})$ were also obtained from Fisher Chemicals (Illkirch, France). Only Milli-Q water $(\rho=18 \mathrm{M} \Omega \mathrm{cm})$ was used in the preparation of aqueous solutions and to rinse gold nanoparticles. The ultrafiltration cell (Model 8400, $400 \mathrm{~mL}$ ) and membranes (regenerated cellulose) were purchased from Merck Millipore (Molsheim, France). Gold nanoparticles were filtered using a $0.22 \mu \mathrm{m}$ pore diameter polymer membrane purchased from Osmonics Inc (Penang, Malaysia). All chemicals were used without further purification.

\subsection{Preparation of Bare TiONts and Amine-Functionalized TiONts (TiONts-APTES)}

Bare TiONts were synthesized by a hydrothermal method. A total of $1 \mathrm{~g}$ of precursor (titanium dioxide rutile) was ultrasonicated (30 min, $375 \mathrm{~W}$, Sonics Vibra-Cells (Newton, CT, USA) in a $\mathrm{NaOH}$ aqueous solution $(10 \mathrm{M}, 250 \mathrm{~mL})$. Subsequently, the mixture was transferred into a Teflon reactor with mechanical stirring and heating at $155^{\circ} \mathrm{C}$ for $36 \mathrm{~h}$. TiONts were washed by centrifugation $(24,000 \times g$ for $10 \mathrm{~min}$ ), dialysis (Cellu.Sep tubular membranes of 12-14 kDa), and ultrafiltration (regenerated cellulose membranes with a molecular weight cut-off (MWCO) of $100 \mathrm{kDa}$ ) [30,31,43]. Subsequently, TiONts were functionalized with silane-coupling agent, presenting high reactivity with hydroxyl groups on 
the surface of material. Consequently, TiONts were modified with APTES (the molar ratio between hydroxyl functions of TiONts and APTES was 1:3) via hydrolysis and condensation in a solution of water and ethanol (50:50 v:v) under magnetic stirring at $60^{\circ} \mathrm{C}$ for $5 \mathrm{~h}$ (TiONts-APTES) $[39,47,67]$. After the reaction, suspension was ultrafiltered ( $100 \mathrm{kDa})$ to eliminate the excess of APTES. Finally, the TiONts-APTES were freeze-dried.

\subsection{Synthesis of Dithiolated Diethylenetriaminepentaacetic Acid (DTDTPA) and Functionalized Gold Nanoparticles Synthesis (Au@DTDTPA NPs)}

The synthesis of Au@DTDTPA NPs was described by Alric et al. [52,63]. Briefly, $5.6 \times 10^{-3} \mathrm{~mol}$ of dithiolated diethylenetriaminepentaacetic acid bis(anhydride) (DTPA-BA) was dissolved in DMF and heated to $70^{\circ} \mathrm{C}$. Then, $1.23 \times 10^{-2} \mathrm{~mol}$ of aminoethanethiol was dissolved in DMF and $1.74 \mathrm{~mL}$ of triethylamine. This solution was added and mixture was stirred magnetically at $70^{\circ} \mathrm{C}$ overnight. Subsequently, the solution was cooled to $25^{\circ} \mathrm{C}$ and placed in an ice bath. A white powder $\left(\mathrm{NEt}_{3} \cdot \mathrm{HCl}\right)$ was seen to precipitate out and was filtered. After filtration, chloroform washing, and drying under vacuum, DTDTPA was obtained as a white powder.

Gold nanoparticles were synthesized adapting Brust's protocol in the presence of DTDTPA to control size and colloidal stability [72]. In a typical preparation of gold nanoparticles, $5.1 \times 10^{-5} \mathrm{~mol}$ of $\mathrm{HAuCl}_{4} \cdot 3 \mathrm{H}_{2} \mathrm{O}$ was dissolved in methanol and mixed with $9.4 \times 10^{-5} \mathrm{~mol}$ of DTDTPA in water, and acetic acid was added to the gold salt solution while continuously stirring the mixture. After $5 \mathrm{~min}, 5 \times 10^{-5} \mathrm{~mol}$ of $\mathrm{NaBH}_{4}$ dissolved in water was added to the orange mixture under vigorous stirring at $25{ }^{\circ} \mathrm{C}$ for $1 \mathrm{~h}$, before adding $\mathrm{HCl}$ solution. After partial removal of the solvent under reduced pressure at a maximum temperature of $40^{\circ} \mathrm{C}$, the precipitate was filtered. The resulting black powder (Au@DTDTPA NPs) was dried and either stored as a solid or dispersed in $10 \mathrm{~mL}$ of $0.01 \mathrm{M}$ $\mathrm{NaOH}$ solution.

\subsection{AuNP-Coated TiONt (TiONts-AuNPs) Synthesis}

TiONts-APTES were mixed with Au@DTDTPA NPs in $40 \mathrm{~mL}$ of phosphate buffered saline $(0.1 \mathrm{M}$; $\mathrm{pH}$ 7.4). A large excess of EDC and NHS were added beforehand on water ( $\mathrm{pH} 5$ ), to activate the carboxylate functions of the DTDTPA on the surface of AuNPs, during 90 min under magnetic stirring. The molar ratio between amines on the surface of the TiONts-APTES and the carboxylate functions of the DTDTPA was 1:0.6. The reaction took place under magnetic stirring for $24 \mathrm{~h}$. Then, TiONts-AuNPs were washed by ultrafiltration $(500 \mathrm{kDa})$ and freeze-dried. Elimination of non-grafted AuNPs was optimized by UV-control of washing waters.

\subsection{Grafting of Polyethylene Glycol (PEG $\mathrm{B}_{3000}$ ) on TiONts-AuNPs}

Heterobifunctional polymers $\mathrm{HS}-\mathrm{PEG}_{3000}-\mathrm{COOH}$ were activated with PyBOP in a molar ratio of 1:1. The reaction took place in DMSO in the presence of the organic base DIEA (excess) under magnetic stirring and nitrogen flow for $30 \mathrm{~min}$. TiONts-AuNPs were dispersed in DMSO and added to activation solution for $24 \mathrm{~h}$ under magnetic stirring and nitrogen flow at $25{ }^{\circ} \mathrm{C}$. Polymers were grafted on the remaining amine functions of APTES. The molar ratio was 1:1 between amine functions (initially present on TiONts-APTES even if gold nanoparticles were present) and polymers. Finally, the product (TiONts-AuNPs-PEG 3000 ) was washed by centrifugation $(20,000 \times g$ for $20 \mathrm{~min})$, then purified by ultrafiltration $(500 \mathrm{kDa})$ and freeze-dried.

\subsection{Activation and Grafting of the Therapeutic Agent: DTX}

Activation and grafting of the therapeutic agent have been described by Loiseau et al. [43]. First, DTX and PMPI (DTX-PMP) were dissolved in DMSO and then added in borate buffered saline. The molar ratio was $1: 4$, respectively, under magnetic stirring at $25^{\circ} \mathrm{C}$ for $24 \mathrm{~h}$. The solution of DTX-PMPI was dialyzed $(0.5-1 \mathrm{kDa})$ and freeze-dried to obtain a yellowish powder. TiONts-AuNPs-PEG $3000-\mathrm{DTX}$ were synthesized from TiONts-AuNPs-PEG 3000 and DTX-PMPI (large excess) using TCEP in PBS 
(0.1 M; pH 7.4). The mixture was homogenized beforehand in an ultrasonic bath and placed under magnetic stirring for $24 \mathrm{~h}$ at $25^{\circ} \mathrm{C}$. TiONts-AuNPs-PEG ${ }_{3000}$-DTX were dialyzed, ultrafiltered $(500 \mathrm{kDa})$, and freeze-dried.

\subsection{Characterization Techniques of Nanohybrids}

\subsubsection{Thermogravimetric Analysis (TGA)}

The amount of the molecules on the surface of the TiONts after each grafting step was determined by TGA (TA instrument, Discovery TGA (New Castle, DE, USA)). An air flow rate of $25 \mathrm{~mL} \cdot \mathrm{min}^{-1}$ and a temperature ramp of $10{ }^{\circ} \mathrm{C} \cdot \mathrm{min}^{-1}$ from 50 to $800{ }^{\circ} \mathrm{C}$ were used for measurements.

\subsubsection{Surface Area Measurements}

Specific surface area measurements were carried out using a Micromeritics Tristar II apparatus. Samples were outgassed in situ under 20 mTorr pressure for $16 \mathrm{~h}$ at $100{ }^{\circ} \mathrm{C}$. Brunauer-Emmett-Teller (BET) method $\left(\mathrm{S}_{\mathrm{BET}}\right)$ was used in the calculation of specific surface area value from $\mathrm{N}_{2}$ gas adsorption.

\subsubsection{Transmission Electron Microscopy (TEM)}

Nanotube morphology and agglomeration state characterization were carried out with a JEOL JEM-2100F, operating at an accelerating voltage of $200 \mathrm{kV}$ and fitted with an ultra-high pole-piece achieving a point-to-point resolution of $0.19 \mathrm{~nm}$. HAADF-STEM micrographs of AuNP-loaded TiONts were taken on this instrument, equipped with a field emission gun (FEG) type cathode. Samples were prepared by dropping a dilute suspension of powders onto the carbon-coated copper grids.

\subsubsection{Inductively Coupled Plasma (ICP) Spectroscopy}

Determination of titanium and gold contents in final nanohybrids was performed by ICP coupled to mass spectrometry (ICP-MS) analysis (ThermoScientific iCAP 6000 series ICP Spectrometer (Waltham, MA, USA)). A total of $2 \mathrm{mg}$ of final nanohybrids were dissolved in aqua regia at $40{ }^{\circ} \mathrm{C}$. The resulting solutions were diluted in $\mathrm{HNO}_{3}$ for analysis.

\subsubsection{X-ray Photoelectron Spectroscopy (XPS)}

XPS measurements were collected with a PHI 5000 Versaprobe apparatus from a monochromatic $\mathrm{Al} \mathrm{K} \alpha_{1}$ radiation $\left(\mathrm{EK} \alpha_{1}(\mathrm{Al})=1486.7 \mathrm{eV}\right.$ with a $200 \mu \mathrm{m}$ diameter spot size, accelerating voltage of $12 \mathrm{kV}$, and power of $200 \mathrm{~W}$ ). Powders were deposited on an indium sheet and then pressed. A Shirley background was subtracted and Gauss (70\%)-Lorentz (30\%) profiles were applied. Data analysis and curve fittings were realized with CasaXPS processing, and MultiPak software was employed for quantitative analysis. Neutralization process was used to minimize charge effects. Titanium $2 p$ peak $(458.7 \mathrm{eV})$ was used as a reference and allowed the correction of charge effects. The resolution was $2.0 \mathrm{eV}$ for global spectra and $1.3 \mathrm{eV}$ for windows corresponding to selected lines.

\subsubsection{Fourier Transformed Infrared (FTIR) Spectroscopy}

FTIR spectra were recorded on a Bruker Vertex 70v using OPUS version 3.1. using the $\mathrm{KBr}$ method, in which the pellets were made by mixing $2 \mathrm{mg}$ of sample within $198 \mathrm{mg}$ of dried $\mathrm{KBr}$.

\subsection{7. ¿-Potential Measurements}

A Malvern Nano ZS instrument supplied by DTS Nano V7.11 software was used to determine zeta potentials of nanoparticle suspensions. $\mathrm{pH}$ titrations were performed using aqueous solutions of $\mathrm{HCl}(0.1 \mathrm{M}), \mathrm{NaOH}(0.1 \mathrm{M})$, or $\mathrm{NaOH}(0.01 \mathrm{M})$ to adjust the $\mathrm{pH}$ from 3 to 11. Before each measurement, suspension was prepared in aqueous $\mathrm{NaCl}$ solution $\left(10^{-2} \mathrm{M}\right)$ and sonicated for $10 \mathrm{~min}$. 


\subsubsection{UV-Visible}

Shimadzu UV-2550 was used to measure UV-visible absorbance at $600 \mathrm{~nm}$. Turbidimetric studies of nanoparticle suspensions were made in PBS $\left(0.1 \mathrm{M}\right.$; pH 7.4) at $25^{\circ} \mathrm{C}$ (one measurement $/ 5 \mathrm{~min}$ ).

\subsection{Radiolabeling with Indium-111}

For in vivo biodistribution studies, DTDTPA molecules grafted on the nanohybrid were labeled using indium-111 radionuclide ( ${ }^{111}$ In radioactivity half-life $t_{1 / 2}=67.9 \mathrm{~h}$ ) [73]. The preparation of ${ }^{111}$ In-labelled nanohybrids was performed by adding ${ }^{111} \mathrm{In}$ chloride to TiONts-AuNPs-PEG 3000 -DTX in ammonium acetate buffer. Briefly, $386 \mathrm{MBq}$ of ${ }^{111} \mathrm{InCl}_{3}$ in $0.05 \mathrm{M} \mathrm{HCl}(500 \mu \mathrm{L})$ were mixed with $50 \mu \mathrm{L}$ of $1 \mathrm{M} \mathrm{AcONH}_{4} \mathrm{pH} 7.07$ and $450 \mu \mathrm{L}$ of $0.1 \mathrm{M} \mathrm{AcONH}_{4} \mathrm{pH} 5.8$, and $2 \mathrm{mg}$ of TiONts-AuNPs-PEG 3000 -DTX was then added. The resulting mixture $(\mathrm{pH} 5)$ was stirred overnight $(16 \mathrm{~h})$ at $37^{\circ} \mathrm{C}$ in a Thermomixer. Instant thin layer chromatography (ITLC) was performed to determine the radiolabeling yield and to assess the absence of free ${ }^{111} \mathrm{In}$. A total of $1 \mu \mathrm{L}$ of the nanohybrids mixture was spotted on the ITLC-silica gel (SG) strip, which was subsequently eluted with sodium citrate $0.1 \mathrm{M} \mathrm{pH} 5$, and the strip was then analyzed using an AR-2000 radiochromatograph (Eckert and Ziegler, Berlin, Germany; $\mathrm{Rf}=0$ for radiolabeled nanoparticles whereas $\mathrm{Rf}=1$ for small $\left.{ }^{111} \mathrm{In}-\mathrm{AcO}\right)$. At the end of incubation, suspension was centrifuged $(13,000 \times g, 15 \mathrm{~min})$ and supernatant was discarded. The radiolabeled nanohybrids were then suspended in saline prior to injection.

\subsection{Cells and Animals}

Human PC-3 prostate adenocarcinoma cells (ATCC, Manassas, VA, USA) were cultured in Dulbecco's modified Eagle medium (DMEM) with $10 \%$ fetal serum calf (Dutscher, France) at $37^{\circ} \mathrm{C}$, $5 \% \mathrm{CO}_{2}$, and $95 \%$ humidity.

Two days prior to mice injection with cancer cells, whole-body irradiation was performed with a $\gamma$-source (2 Gy, 60Co, BioMep, Bretenières, France). The injection unit included $10 \times 106$ PC-3 cells in $200 \mu \mathrm{L}$ serum-free culture medium containing Matrigel (50:50, $V: V, \mathrm{BD}$ Biosciences). Injection was performed subcutaneously on the right flank of immunosuppressed athymic Balb/c nude male mice which were at least six weeks of age (Charles River, L'Arbresles, France). All mice were housed in our approved animal facility (Centre Georges-François Leclerc, Dijon, France) and all experiments followed the guidelines of the Federation of European Animal Science Associations. All animal studies were conducted in accordance with the European legislation on the use of laboratory animals (directive 2010/63/EU) and approved by accredited ethical committee of the Grand Campus (Dijon, France). The Ministry project agreement numbers are \#13968 (for radiotherapy experiments) and \#7830 (for imaging experiments), and the ethical committee agreement number is 105, with the official name "C2ea Grand Campus".

\subsection{Treatments}

Mice were randomized 20 days post cancer cells injection. To distribute mice among the different treatment groups, a randomization was performed. The aim was to obtain an equivalent average tumor volume (TV) in each treatment group (about $200 \mathrm{~mm}^{3}$ ). Before and during irradiation, each mouse was anesthetized with $2.5 \%$ isoflurane mixed with oxygen (MINERVE system, Esternay, France).

One hour before the first RT fraction, NPs were delivered intratumorally $(50 \mu \mathrm{L}, 1.87 \mu \mathrm{g} / \mu \mathrm{L}$ for TiONts-DTX and $2 \mu \mathrm{g} / \mu \mathrm{L}$ for TiONts-AuNPs-PEG 3000 -DTX, in order to have the same DTX concentration in both cases). Radiotherapy was delivered using three daily fractions of $4 \mathrm{~Gy}$ by a small animal irradiator (SARRP, Xstrahl, United Kingdom), with $225 \mathrm{kV}$ energy X-ray photons and a dose rate of $3.1 \mathrm{~Gy} / \mathrm{min}$. For each RT session, an anterior field and a posterior field were used to irradiate the tumor in a targeted way with a homogeneous dose. 


\subsection{In Vitro Evaluation of Nanohybrid Cytotoxicity}

To evaluate the cytotoxic activity of DTX on the surface of nanohybrids, androgen-independent PC-3 prostate cancer cells were seeded in 96-well plates at a concentration of 3000 cells/well and incubated at $37^{\circ} \mathrm{C}$ in $190 \mu \mathrm{L}$ of drug-free culture medium (DMEM) with $10 \%$ fetal bovine serum (FBS) for $24 \mathrm{~h}$ before treatment (when the cells were at around 20\% confluence). Cytotoxicity assays were performed with four samples at each concentration of free DTX (positive control), Au@DTDTPA NPs, TiONts-AuNPs-PEG 3000 , or TiONts-AuNPs-PEG 3000 -DTX. Tumor cells were incubated $(+10 \mu \mathrm{L}$ of drug in $190 \mu \mathrm{L}$ of culture medium) with a range of equivalent DTX concentrations from 0.5 to $500 \mathrm{nM}$ ( $100 \mathrm{nM}$ of DTX corresponds to $0.2 \mu \mathrm{g}$ of nanohybrids per well from TGA, i.e., a nanohybrid concentration of $\left.1.0 \mu \mathrm{g} . \mathrm{mL}^{-1}\right)$. After $96 \mathrm{~h}$ of incubation, cell viability was evaluated using MTS assay (Promega Corporation, Madison, WI, USA) according to Mirjolet et al. [44,45,74]. Results were expressed as relative absorption at $490 \mathrm{~nm}$ relative to the untreated control.

\subsection{Analysis of TiONts-AuNPs-PEG $3000-D T X$ Biodistribution}

Because the organic shell of Au@DTDTPA NPs ensures the immobilization of ${ }^{111}$ In ions (due to the chelating properties of DTDTPA) [64], TiONts-AuNPS-PEG 3000 -DTX can be radiolabeled. The location of these hybrid nanostructures can therefore be monitored by SPECT. After mice in vivo injection, TiONts were tracked using a NanoSPECT/CT small animal imaging tomographic gamma-camera (Bioscan Inc., Poway, CA, USA). TiONts-AuNPs-PEG 3000 -DTX- ${ }^{111}$ In (50 $\mu \mathrm{L}, 40-60 \mu \mathrm{g}$; $5.7-8.7$ MBq of activity) were injected into nine subcutaneous PC-3 human prostate tumor-bearing mice. In vivo biodistribution at $1 \mathrm{~h}, 3 \mathrm{~h}, 24 \mathrm{~h}, 48 \mathrm{~h}, 72 \mathrm{~h}$, and 6 days after injection was analyzed using SPECT/CT imaging. Then, 10 days post-injection, the 3 imaged animals were sacrificed, and 15 days and 20 days after injection the other mice (three animals per group) were also sacrificed. Tumor, blood, lung, liver, kidney, spleen, bladder, bowel, and heart of each mouse were collected and radioactivity in these samples was measured using a gamma counter (Wizard 1480, Perkin Elmer, Waltham, MA, USA).

\subsection{Evaluation of the Radiotherapeutic Efficacy of TiONts-DTX and TiONts-AuNPs-PEG $G_{3000-D T X}$}

To evaluate the benefit of nanohybrids, tumors were treated with an intratumoral injection of a $50 \mu \mathrm{L}$ TiONts-DTX or TiONts-AuNPs-PEG 3000 -DTX suspension (containing $10.5 \mathrm{nmol}$ of DTX grafted onto $93.5 \mu \mathrm{g}$ of TiONts-DTX and $100 \mu \mathrm{g}$ of TiONts-AuNPs-PEG ${ }_{3000}$-DTX). The gold quantity injected present on TiONts-AuNPs-PEG 3000 -DTX was $15 \mu \mathrm{g}$ Au@DTDTPA/animal (corresponding to $36.1 \mathrm{nmol}$ of Au or 66.5 pmol of 2.6-nm AuNPs). After induction of PC-3 tumors in mice and as soon as the tumors had reached a mean volume of approximately $200 \mathrm{~mm}^{3}$, mice were randomized according to their individual tumor volume into three groups of 67 mice (control IT injection, TiONts-DTX, and TiONts-AuNPs-PEG 3000 -DTX).

To evaluate the effectiveness of treatment, tumor growth was evaluated by the growth retardation parameter (time to reach a volume of $1000 \mathrm{~mm}^{3}$ ). The TV was recorded three times a week using calipers and calculated according to the following formula: TV $=$ thickness $\times$ width $\times$ length $\times 0.5$. Each group included six or seven mice; numbers were calculated considering inter-mouse variability. Tumor growth delay was compared between mice groups using the nonparametric Mann-Whitney test.

\section{Conclusions}

The elaborated nanohybrid (TiONts-AuNPs-PEG $3000-\mathrm{DTX}$ ) was prepared using a step-by-step synthesis allowing for the precise characterization of each grafting step. A thorough characterization of the latter led to substantial results, showing the originality and innovation of the associations, particularly the AuNPs/TiONts combination. Grafting of gold nanoparticles, functionalized with DTDTPA, on the surface of TiONts-APTES was successful thanks to peptidic coupling. This pathway of grafting limited AuNP and TiONt agglomeration and ensured an even distribution of Au@DTDTPA NPs over the surface of TiONts. Moreover, gold nanoparticles provided nanohybrids 
with a remarkable colloidal stability under physiological conditions, improving in vitro and in vivo behavior for targeted biomedical applications. The significant amount of therapeutic agent (DTX) modified by PMPI on the TiONts surface showed that DTX-PMPI were covalently bound with thiol functions (from $\mathrm{PEG}_{3000}$ and DTDTPA) but also via free amine groups (APTES) depending on the $\mathrm{pH}$. Thus, this study confirmed the potent therapeutic effect of our final nanohybrid after DTX grafting onto the surface of nanotubes. In vitro biological assays (MTS) highlighted the cytotoxic activity of DTX present on the surface of TiONts-AuNPs-PEG $3000-D T X$ on human PC-3 prostate adenocarcinoma cells. Although nanohybrids' cytotoxicity was lower than that of DTX alone $\left(\mathrm{IC}_{50}=82 \mathrm{nM}\right.$ versus $3.1 \mathrm{nM}$, respectively), cytotoxic activity remained very high. These results proved a better access of TiONts-AuNPs-PEG $3000-D T X$ to microtubules compared to first generation TiONts-DTX (without Au@DTDTPA NPs) $\left(\mathrm{IC}_{50}=390\right.$ nM) [43], possibly suggesting a better internalization. This observation was not surprising, as new functionalized nanomaterial was better dispersed at physiological $\mathrm{pH}$, and was thus more stable in suspension even though it exhibited a lower $\zeta$-potential indicating a screening effect (the steric hindrance should prevail in this case). In addition, we successfully developed a safe nanocarrier of DTX to directly deliver this drug into prostate tumors (by IT injection), able to maintain it inside tumor cells for longer (at least 20 days, as demonstrated by biodistribution results in Balb/c nude mice), and to prevent its diffusion throughout the body, avoiding side effects. Therefore, the effectiveness of the selected therapeutic agent was improved. After combined IT injection with radiotherapy, TiONts-AuNPs-PEG $3000-\mathrm{DTX}$ nanohybrid improved treatment efficacy by delaying tumor growth compared to the homologous nanohybrids without gold nanoparticles. Gold can increase the effect already demonstrated for TiONts-DTX [49,52]. Finally, these functionalized TiONts appear as promising versatile tools in the biomedical field to fight cancer, prostate cancer in particular.

Supplementary Materials: The following materials are available online at http://www.mdpi.com/2072-6694/11/ 12/1962/s1. Figure S1: Transmission electron microscopy (TEM) images show (a) the spiral morphology with an internal cavity of titanate nanotubes and $(\mathbf{b}, \mathbf{c})$ the evolution of TiONt dispersion before and after APTES grafting, respectively, Figure S2: Theoretical calculation of the hydroxyl rates on bare TiONts, Figure S3: Theoretical calculation for functionalized TiONt rate of grafting, Figure S4: TGA and derivative curves of Au@DTDTPA NPs under air atmosphere, Figure S5: (a) $\mathrm{Ti}_{2 p}$ and (b) $\mathrm{Au}_{4 \mathrm{f}}$ peaks in XPS spectra for TiONts-AuNPs, Figure S6: HAADF-STEM images of TiONts-AuNPs-PEG 3000 , Figure S7: (a) Maleimide reacts specifically with a thiol function at $\mathrm{pH}<7.5$ and (b) loses its specificity to react either with a thiol function or with amine function at $\mathrm{pH}$ >7.5, Figure S8: (a) Polymer (Boc-NH-PEG $3000-\mathrm{COOH} ; M W=3,173 \mathrm{~g} \cdot \mathrm{mol}^{-1}$ ) having an inactive function (Boc) and carboxyl function to react with an amine group via peptide coupling and (b) TGA curves showing the adsorption of DTX-PMPI upon contact between TiONts-PEG $3000-$ Boc and DTX-PMPI (TiONts-DTX were washed by dialysis and ultrafiltration $(100 \mathrm{kDa})$ ), Figure S9: Therapeutic effect as function of time of control, TiONts-PEG $3000-\mathrm{DTX}$, and TiONts-AuNPs-PEG 3000 -DTX, associated or not with radiotherapy (RT) with three daily fractions of 4 Gy, $24 \mathrm{~h}$ after injection into PC-3 xenografted tumors $(n=6,7)$.

Author Contributions: Conceptualization, N.M., J.B., S.R. and C.M. initiated, N.M. and C.M. directed the project and N.M. and C.M. contributed equally in this work; A.L., S.R. and J.B. designed the chemical experiments; A.L. performed the synthesis and characterization of nanohybrids; C.M. managed all biological experiments; A.O., M.M., and R.B. performed the ${ }^{111}$ In-labelling of nanohybrids and biodistribution analysis; C.M. performed in vitro tests and evaluation of radiotherapeutic effect; R.C. investigated TEM and HAADF-STEM images; N.M.S. and S.R. provided samples of DTDTPA-modified gold nanoparticles. A.L. wrote the manuscript; J.B., C.M., and N.M. supervised and corrected the paper. All authors contributed to the final manuscript.

Funding: This work was supported by the Cancéropôle Est through the call "Emergence 2015" (Région Bourgogne Franche Comté). This work is also part of the project "Nano2Bio", funded by the "Universite de Bourgogne" and the "Conseil Régional de Bourgogne" through the "Plan d'Actions Régional pour l'Innovation (PARI)", the European Union through the PO FEDER-FSE Bourgogne 2014/2020 programs and this work has been supported by the EIPHI Graduate School (contract "ANR-17-EURE-0002").

Acknowledgments: The authors would like to thank Olivier Heintz (ICB) for XPS measurements; Fadoua Sallem (ICB) for preparation; Myriam Heydel (Sayens) for ICP measurements; and Véronique Morgand (CGFL), Camille Drouet (CGFL), and Mélanie Guillemin (CGFL) for their help during in vitro and in vivo assays. This work was performed within a regional center of excellence in pharmaco-imaging (Pharmimage GIE, Pharmaco-imaging "groupement d'intérêt scientifique" (GIS). Finally, the authors also thank Isabel Gregoire (CGFL) for editorial assistance.

Conflicts of Interest: The authors declare no conflict of interest. 


\section{References}

1. Shevchenko, E.V.; Talapin, D.V.; Murray, C.B.; O’Brien, S. Structural Characterization of Self-Assembled Multifunctional Binary Nanoparticle Superlattices. J. Am. Chem. Soc. 2006, 128, 3620-3637. [CrossRef]

2. Rawla, P. Epidemiology of Prostate Cancer. World J. Oncol. 2019, 10, 63-89. [CrossRef]

3. National Cancer Institute. Available online: http://seer.cancer.gov/statfacts/html/prost.html (accessed on 10 October 2019).

4. Ferlay, J.; Colombet, M.; Soerjomataram, I.; Dyba, T.; Randi, G.; Bettio, M.; Gavin, A.; Visser, O.; Bray, F. Cancer incidence and mortality patterns in Europe: Estimates for 40 countries and 25 major cancers in 2018. Eur. J. Cancer 2018, 103, 356-387. [CrossRef]

5. Kuroda, K.; Liu, H.; Kim, S.; Guo, M.; Navarro, V.; Bander, N.H. Docetaxel down-regulates the expression of androgen receptor and prostate-specific antigen but not prostate-specific membrane antigen in prostate cancer cell lines: Implications for PSA surrogacy. Prostate 2009, 69, 1579-1585. [CrossRef]

6. Armstrong, C.M.; Gao, A.C. Drug resistance in castration resistant prostate cancer: Resistance mechanisms and emerging treatment strategies. Am. J. Clin. Exp. Urol. 2015, 3, 64-76.

7. Galsky, M.D.; Vogelzang, N.J. Docetaxel-based combination therapy for castration-resistant prostate cancer. Ann. Oncol. 2010, 21, 2135-2144. [CrossRef]

8. Bolla, M.; Hannoun-Levi, J.M.; Ferrero, J.-M.; Maingon, P.; Buffet-Miny, J.; Bougnoux, A.; Bauer, J.; Descotes, J.-L.; Fourneret, P.; Jover, F.; et al. Concurrent and adjuvant docetaxel with three-dimensional conformal radiation therapy plus androgen deprivation for high-risk prostate cancer: Preliminary results of a multicentre phase II trial. Radiother. Oncol. 2010, 97, 312-317. [CrossRef]

9. Larsen, A.K.; Escargueil, A.E.; Skladanowski, A. Resistance mechanisms associated with altered intracellular distribution of anticancer agents. Pharmacol. Ther. 2000, 85, 217-229. [CrossRef]

10. Morgillo, F.; Lee, H.-Y. Resistance to epidermal growth factor receptor-targeted therapy. Drug Resist. Update 2005, 8, 298-310. [CrossRef]

11. Sahoo, S.K.; Parveen, S.; Panda, J.J. The present and future of nanotechnology in human health care. Nanomedicine 2007, 3, 20-31. [CrossRef]

12. Parveen, S.; Sahoo, S.K. Polymeric nanoparticles for cancer therapy. J. Drug Target. 2008, 16, $108-123$. [CrossRef]

13. Parhi, P.; Mohanty, C.; Sahoo, S.K. Nanotechnology-based combinational drug delivery: An emerging approach for cancer therapy. Drug Discov. Today 2012, 17, 1044-1052. [CrossRef]

14. Lammers, T.; Kiessling, F.; Hennink, W.E.; Storm, G. Nanotheranostics and image-guided drug delivery: Current concepts and future directions. Mol. Pharm. 2010, 7, 1899-1912. [CrossRef]

15. Muthu, M.S.; Leong, D.T.; Mei, L.; Feng, S.-S. Nanotheranostics-Application and Further Development of Nanomedicine Strategies for Advanced Theranostics. Theranostics 2014, 4, 660-677. [CrossRef]

16. Maeda, H. The enhanced permeability and retention (EPR) effect in tumor vasculature: The key role of tumor-selective macromolecular drug targeting. Adv. Enzyme Regul. 2001, 41, 189-207. [CrossRef]

17. Allen, T.M. Ligand-targeted therapeutics in anticancer therapy. Nat. Rev. Cancer 2002, 2, 750-763. [CrossRef]

18. Cho, K.; Wang, X.; Nie, S.; Shin, D.M. Therapeutic nanoparticles for drug delivery in cancer. Clin. Cancer Res. 2008, 14, 1310-1316. [CrossRef]

19. Sun, T.; Zhang, Y.S.; Pang, B.; Hyun, D.C.; Yang, M.; Xia, Y. Engineered Nanoparticles for Drug Delivery in Cancer Therapy. Angew. Chem. Int. Ed. 2014, 53, 12320-12364. [CrossRef]

20. McDevitt, M.R.; Chattopadhyay, D.; Kappel, B.J.; Jaggi, J.S.; Schiffman, S.R.; Antczak, C.; Njardarson, J.T.; Brentjens, R.; Scheinberg, D.A. Tumor targeting with antibody-functionalized, radiolabeled carbon nanotubes. J. Nucl. Med. 2007, 48, 1180-1189. [CrossRef]

21. Lazzara, G.; Cavallaro, G.; Panchal, A.; Fakhrullin, R.; Stavitskaya, A.; Vinokurov, V.; Lvov, Y. An assembly of organic-inorganic composites using halloysite clay nanotubes. Curr. Opin. Colloid Interface Sci. 2018, 35, 42-50. [CrossRef]

22. Ji, S.-R.; Liu, C.; Zhang, B.; Yang, F.; Xu, J.; Long, J.; Jin, C.; Fu, D.-L.; Ni, Q.-X.; Yu, X.-J. Carbon nanotubes in cancer diagnosis and therapy. Biochim. Biophys. Acta Rev. Cancer 2010, 1806, 29-35. [CrossRef]

23. Liu, Z.; Sun, X.; Nakayama-Ratchford, N.; Dai, H. Supramolecular Chemistry on Water-Soluble Carbon Nanotubes for Drug Loading and Delivery. ACS Nano 2007, 1, 50-56. [CrossRef] 
24. Chen, J.; Chen, S.; Zhao, X.; Kuznetsova, L.V.; Wong, S.S.; Ojima, I. Functionalized Single-Walled Carbon Nanotubes as Rationally Designed Vehicles for Tumor-Targeted Drug Delivery. J. Am. Chem. Soc. 2008, 130, 16778-16785. [CrossRef]

25. Vaisman, L.; Wagner, H.D.; Marom, G. The role of surfactants in dispersion of carbon nanotubes. Adv. Colloid Interface Sci. 2006, 128-130, 37-46. [CrossRef]

26. Lvov, Y.M.; Shchukin, D.G.; Möhwald, H.; Price, R.R. Halloysite Clay Nanotubes for Controlled Release of Protective Agents. ACS Nano 2008, 2, 814-820. [CrossRef]

27. Vergaro, V.; Abdullayev, E.; Lvov, Y.M.; Zeitoun, A.; Cingolani, R.; Rinaldi, R.; Leporatti, S. Cytocompatibility and Uptake of Halloysite Clay Nanotubes. Biomacromolecules 2010, 11, 820-826. [CrossRef]

28. Tarasova, E.; Naumenko, E.; Rozhina, E.; Akhatova, F.; Fakhrullin, R. Cytocompatibility and uptake of polycations-modified halloysite clay nanotubes. Appl. Clay Sci. 2019, 169, 21-30. [CrossRef]

29. Bavykin, D.V.; Walsh, F.C. Titanate and Titania Nanotubes: Synthesis, Properties and Applications; Royal Society of Chemistry: Cambridge, UK, 2010; p. 154.

30. Papa, A.-L.; Millot, N.; Saviot, L.; Chassagnon, R.; Heintz, O. Effect of Reaction Parameters on Composition and Morphology of Titanate Nanomaterials. J. Phys. Chem. C 2009, 113, 12682-12689. [CrossRef]

31. Sallem, F.; Chassagnon, R.; Megriche, A.; El Maaoui, M.; Millot, N. Effect of mechanical stirring and temperature on dynamic hydrothermal synthesis of titanate nanotubes. J. Alloys Compd. 2017, 722, 785-796. [CrossRef]

32. Kasuga, T.; Hiramatsu, M.; Hoson, A.; Sekino, T.; Niihara, K. Formation of titanium oxide nanotube. Langmuir 1998, 14, 3160-3163. [CrossRef]

33. Fenyvesi, F.; Kónya, Z.; Rázga, Z.; Vecsernyés, M.; Kása, P.; Pintye-Hódi, K.; Bácskay, I. Investigation of the Cytotoxic Effects of Titanate Nanotubes on Caco-2 Cells. AAPS PharmSciTech 2014, 15, 858-861. [CrossRef]

34. Oh, S.-H.; Finõnes, R.R.; Daraio, C.; Chen, L.-H.; Jin, S. Growth of nano-scale hydroxyapatite using chemically treated titanium oxide nanotubes. Biomaterials 2005, 26, 4938-4943. [CrossRef]

35. Niu, L.; Shao, M.; Wang, S.; Lu, L.; Gao, H.; Wang, J. Titanate nanotubes: Preparation, characterization, and application in the detection of dopamine. J. Mater. Sci. 2008, 43, 1510-1514. [CrossRef]

36. Papa, A.L.; Dumont, L.; Vandroux, D.; Millot, N. Titanate nanotubes: Towards a novel and safer nanovector for cardiomyocytes. Nanotoxicology 2013, 7, 1131-1142. [CrossRef]

37. Niu, H.; Cai, Y. Preparation of amino-modified titanate nanotubes and its striking adsorption ability to duplex DNA. J. Nanoparticle Res. 2011, 13, 39-43. [CrossRef]

38. Papa, A.-L.; Maurizi, L.; Vandroux, D.; Walker, P.; Millot, N. Synthesis of Titanate Nanotubes Directly Coated with USPIO in Hydrothermal Conditions: A New Detectable Nanocarrier. J. Phys. Chem. C 2011, 115, 19012-19017. [CrossRef]

39. Paris, J.; Bernhard, Y.; Boudon, J.; Heintz, O.; Millot, N.; Decreau, R.A. Phthalocyanine-titanate nanotubes: A promising nanocarrier detectable by optical imaging in the so-called imaging window. RSC Adv. 2015, 5, 6315-6322. [CrossRef]

40. Sallem, F.; Boudon, J.; Heintz, O.; Severin, I.; Megriche, A.; Millot, N. Synthesis and characterization of chitosan-coated titanate nanotubes: Towards a new safe nanocarrier. Dalton Trans. 2017, 46, 15386-15398. [CrossRef]

41. Sruthi, S.; Loiseau, A.; Boudon, J.; Sallem, F.; Maurizi, L.; Mohanan, P.V.; Lizard, G.; Millot, N. In vitro interaction and biocompatibility of titanate nanotubes with microglial cells. Toxicol. Appl. Pharmacol. 2018, 353, 74-86. [CrossRef]

42. Baati, T.; Kefi, B.B.; Aouane, A.; Njim, L.; Chaspoul, F.; Heresanu, V.; Kerkeni, A.; Neffati, F.; Hammami, M. Biocompatible titanate nanotubes with high loading capacity of genistein: Cytotoxicity study and anti-migratory effect on U87-MG cancer cell lines. RSC Adv. 2016, 6, 101688-101696. [CrossRef]

43. Loiseau, A.; Boudon, J.; Mirjolet, C.; Crehange, G.; Millot, N. Taxane-Grafted Metal-Oxide Nanoparticles as a New Theranostic Tool against Cancer: The Promising Example of Docetaxel-Functionalized Titanate Nanotubes on Prostate Tumors. Adv. Healthc. Mater. 2017, 6, 1700245. [CrossRef] [PubMed]

44. Mirjolet, C.; Boudon, J.; Loiseau, A.; Chevrier, S.; Boidot, R.; Oudot, A.; Collin, B.; Martin, E.; Joy, P.A.; Millot, N. Docetaxel-titanate nanotubes enhance radiosensitivity in an androgen-independent prostate cancer model. Int. J. Nanomed. 2017, 12, 6357-6364. [CrossRef] 
45. Mirjolet, C.; Papa, A.-L.; Créhange, G.; Raguin, O.; Seignez, C.; Paul, C.; Truc, G.; Maingon, P.; Millot, N. The radiosensitization effect of titanate nanotubes as a new tool in radiation therapy for glioblastoma: A proof-of-concept. Radiother. Oncol. 2013, 108, 136-142. [CrossRef] [PubMed]

46. Decuzzi, P.; Godin, B.; Tanaka, T.; Lee, S.Y.; Chiappini, C.; Liu, X.; Ferrari, M. Size and shape effects in the biodistribution of intravascularly injected particles. J. Control. Release 2010, 141, 320-327. [CrossRef] [PubMed]

47. Papa, A.-L.; Boudon, J.; Bellat, V.; Loiseau, A.; Bisht, H.; Sallem, F.; Chassagnon, R.; Berard, V.; Millot, N. Dispersion of titanate nanotubes for nanomedicine: Comparison of PEI and PEG nanohybrids. Dalton Trans. 2015, 44, 739-746. [CrossRef]

48. James, F.H.; Daniel, N.S.; Henry, M.S. The use of gold nanoparticles to enhance radiotherapy in mice. Phys. Med. Biol. 2004, 49, N309.

49. Schuemann, J.; Berbeco, R.; Chithrani, D.B.; Cho, S.H.; Kumar, R.; McMahon, S.J.; Sridhar, S.; Krishnan, S. Roadmap to Clinical Use of Gold Nanoparticles for Radiation Sensitization. Int. J. Radiat. Oncol. Biol. Phys. 2016, 94, 189-205. [CrossRef]

50. Subiel, A.; Ashmore, R.; Schettino, G. Standards and Methodologies for Characterizing Radiobiological Impact of High-Z Nanoparticles. Theranostics 2016, 6, 1651-1671. [CrossRef]

51. Chen, J.; Saeki, F.; Wiley, B.J.; Cang, H.; Cobb, M.J.; Li, Z.-Y.; Au, L.; Zhang, H.; Kimmey, M.B.; Li, X.; et al. Gold Nanocages: Bioconjugation and Their Potential Use as Optical Imaging Contrast Agents. Nano Lett. 2005, 5, 473-477. [CrossRef]

52. Alric, C.; Serduc, R.; Mandon, C.; Taleb, J.; Le Duc, G.; Le Meur-Herland, A.; Billotey, C.; Perriat, P.; Roux, S.; Tillement, $\mathrm{O}$. Gold nanoparticles designed for combining dual modality imaging and radiotherapy. Gold Bull. 2008, 41, 90-97. [CrossRef]

53. Park, J.-A.; Kim, H.-K.; Kim, J.-H.; Jeong, S.-W.; Jung, J.-C.; Lee, G.-H.; Lee, J.; Chang, Y.; Kim, T.-J. Gold nanoparticles functionalized by gadolinium-DTPA conjugate of cysteine as a multimodal bioimaging agent. Bioorg. Med. Chem. Lett. 2010, 20, 2287-2291. [CrossRef] [PubMed]

54. Mieszawska, A.J.; Mulder, W.J.M.; Fayad, Z.A.; Cormode, D.P. Multifunctional Gold Nanoparticles for Diagnosis and Therapy of Disease. Mol. Pharm. 2013, 10, 831-847. [CrossRef] [PubMed]

55. Yang, P.-H.; Sun, X.; Chiu, J.-F.; Sun, H.; He, Q.-Y. Transferrin-Mediated Gold Nanoparticle Cellular Uptake. Bioconjugate Chem. 2005, 16, 494-496. [CrossRef]

56. Ghosh, P.; Han, G.; De, M.; Kim, C.K.; Rotello, V.M. Gold nanoparticles in delivery applications. Adv. Drug Deliv. Rev. 2008, 60, 1307-1315. [CrossRef]

57. Dykman, L.; Khlebtsov, N. Gold nanoparticles in biomedical applications: Recent advances and perspectives. Chem. Soc. Rev. 2012, 41. [CrossRef]

58. Figueiredo, S.; Cabral, R.; Luís, D.; Fernandes, A.R.; Baptista, P.V. Conjugation of Gold nanoparticles and liposomes for combined vehicles of drug delivery in cancer. Nanomedicine 2014, 48, 48-69.

59. Brun, E.; Sanche, L.; Sicard-Roselli, C. Parameters governing gold nanoparticle X-ray radiosensitization of DNA in solution. Colloids Surf. B Biointerfaces 2009, 72, 128-134. [CrossRef]

60. Miladi, I.; Alric, C.; Dufort, S.; Mowat, P.; Dutour, A.; Mandon, C.; Laurent, G.; Bräuer-Krisch, E.; Herath, N.; Coll, J.L.; et al. The In Vivo Radiosensitizing Effect of Gold Nanoparticles Based MRI Contrast Agents. Small 2014, 10, 1116-1124. [CrossRef]

61. Butterworth, K.T.; Nicol, J.R.; Ghita, M.; Rosa, S.; Chaudhary, P.; McGarry, C.K.; McCarthy, H.O.; Jimenez-Sanchez, G.; Bazzi, R.; Roux, S. Preclinical evaluation of gold-DTDTPA nanoparticles as theranostic agents in prostate cancer radiotherapy. Nanomedicine 2016, 11, 2035-2047. [CrossRef]

62. Debouttière, P.J.; Roux, S.; Vocanson, F.; Billotey, C.; Beuf, O.; Favre-Réguillon, A.; Lin, Y.; Pellet-Rostaing, S.; Lamartine, R.; Perriat, P.; et al. Design of Gold Nanoparticles for Magnetic Resonance Imaging. Adv. Funct. Mater. 2006, 16, 2330-2339. [CrossRef]

63. Alric, C.; Taleb, J.; Le Duc, G.; Mandon, C.; Billotey, C.; Le Meur-Herland, A.; Brochard, T.; Vocanson, F.; Janier, M.; Perriat, P.; et al. Gadolinium chelate coated gold nanoparticles as contrast agents for both X-ray computed tomography and magnetic resonance imaging. J. Am. Chem. Soc. 2008, 130, 5908-5915. [CrossRef] [PubMed]

64. Alric, C.; Miladi, I.; Kryza, D.; Taleb, J.; Lux, F.; Bazzi, R.; Billotey, C.; Janier, M.; Perriat, P.; Roux, S.; et al. The biodistribution of gold nanoparticles designed for renal clearance. Nanoscale 2013, 5, 5930-5939. [CrossRef] [PubMed] 
65. Laprise-Pelletier, M.; Lagueux, J.; Côté, M.F.; LaGrange, T.; Fortin, M.A. Low-Dose Prostate Cancer Brachytherapy with Radioactive Palladium-Gold Nanoparticles. Adv. Healthc. Mater. 2017, 6, 1601120. [CrossRef] [PubMed]

66. Zhu, M.; Lerum, M.Z.; Chen, W. How to Prepare Reproducible, Homogeneous, and Hydrolytically Stable Aminosilane-Derived Layers on Silica. Langmuir 2012, 28, 416-423. [CrossRef] [PubMed]

67. Pontón, P.I.; d'Almeida, J.R.M.; Marinkovic, B.A.; Savić, S.M.; Mancic, L.; Rey, N.A.; Morgado, E.; Rizzo, F.C. The effects of the chemical composition of titanate nanotubes and solvent type on 3-aminopropyltriethoxysilane grafting efficiency. Appl. Surf. Sci. 2014, 301, 315-322. [CrossRef]

68. Thomas, G.; Demoisson, F.; Boudon, J.; Millot, N. Efficient functionalization of magnetite nanoparticles with phosphonate using a one-step continuous hydrothermal process. Dalton Trans. 2016, 45, 10821-10829. [CrossRef]

69. Rouxhet, P.G.; Genet, M.J. XPS analysis of bio-organic systems. Surf. Interface Anal. 2011, 43, 1453-1470. [CrossRef]

70. Perry, J.L.; Reuter, K.G.; Kai, M.P.; Herlihy, K.P.; Jones, S.W.; Luft, J.C.; Napier, M.; Bear, J.E.; DeSimone, J.M. PEGylated PRINT nanoparticles: The impact of PEG density on protein binding, macrophage association, biodistribution, and pharmacokinetics. Nano Lett. 2012, 12, 5304-5310. [CrossRef]

71. Wang, X.; Ma, D.; Olson, W.C.; Heston, W.D. In vitro and in vivo responses of advanced prostate tumors to PSMA ADC, an auristatin-conjugated antibody to prostate-specific membrane antigen. Mol. Cancer Ther. 2011, 10, 1728-1739. [CrossRef]

72. Brust, M.; Fink, J.; Bethell, D.; Schiffrin, D.J.; Kiely, C. Synthesis and reactions of functionalised gold nanoparticles. J. Chem. Soc. Chem. Commun. 1995, 1655-1656. [CrossRef]

73. Lee, D.S.; Im, H.J.; Lee, Y.S. Radionanomedicine: Widened perspectives of molecular theragnosis. Nanomedicine 2015, 11, 795-810. [CrossRef] [PubMed]

74. Mirjolet, J.; Barberi-Heyob, M.; Merlin, J.; Marchal, S.; Etienne, M.; Milano, G.; Bey, P. Thymidylate synthase expression and activity: Relation to S-phase parameters and 5-fluorouracil sensitivity. Br. J. Cancer 1998, 78, 62-68. [CrossRef] [PubMed]

(C) 2019 by the authors. Licensee MDPI, Basel, Switzerland. This article is an open access article distributed under the terms and conditions of the Creative Commons Attribution (CC BY) license (http://creativecommons.org/licenses/by/4.0/). 